\title{
Uterine uptake of diazepam and quantification by gas chromatography/mass spectrometry
}

\author{
Steven Scott Wolfe \\ West Virginia University
}

Follow this and additional works at: https://researchrepository.wvu.edu/etd

\section{Recommended Citation}

Wolfe, Steven Scott, "Uterine uptake of diazepam and quantification by gas chromatography/mass spectrometry" (2003). Graduate Theses, Dissertations, and Problem Reports. 1755.

https://researchrepository.wvu.edu/etd/1755

This Thesis is protected by copyright and/or related rights. It has been brought to you by the The Research Repository @ WVU with permission from the rights-holder(s). You are free to use this Thesis in any way that is permitted by the copyright and related rights legislation that applies to your use. For other uses you must obtain permission from the rights-holder(s) directly, unless additional rights are indicated by a Creative Commons license in the record and/ or on the work itself. This Thesis has been accepted for inclusion in WVU Graduate Theses, Dissertations, and Problem Reports collection by an authorized administrator of The Research Repository @ WVU. For more information, please contact researchrepository@mail.wvu.edu. 


\title{
Uterine Uptake of Diazepam and Quantification by Gas Chromatography/Mass Spectrometry
}

\author{
Steven Scott Wolfe
}

\section{Thesis}

Submitted to the School of Pharmacy

At

West Virginia University

In Partial Fulfillment of the Requirement for

\section{The Degree of Master of Science}

In

Basic Pharmaceutical Science

Patrick Callery, Ph.D., Chair

Timothy Tracy, Ph.D.

Fred King, Ph.D.

Department of Basic Pharmaceutical Science

Morgantown, WV

2003

Keywords: Diazepam, Transdermal Drug Delivery, Gas Chromatography/Mass Spectrometry 


\section{ABSTRACT \\ Uterine Uptake of Diazepam and Quantification by Gas Chromatography/Mass Spectrometry}

\section{Steven Scott Wolfe}

One of the difficulties in drug delivery is transporting the compound of interest to the target organ while minimizing exposure to the rest of the body. Intravenous administration is effective in the delivery of drugs and results in high bioavailability leading to very rapid systemic distribution. Oral dosing of drugs is the most popular route because of its ease of administration, but it is subject to first pass metabolism by the liver which can greatly reduce the bioavailability of the parent compound. Patients undergoing hysterectomy were recruited for a study in which they were anesthetized and $5 \mathrm{mg}$ of diazepam in gel was applied directly to the cervix by a patented drug delivery device (CerviPrep ${ }^{\mathrm{TM}}$ ) consisting of a modified plastic syringe with a rounded cup on the end. The operation was then begun and blood samples were taken from a peripheral vein at $0,5,10,15$, and 30 minutes during drug administration. Samples were also taken from the uterine vein and uterine capillary bed at 30-45 minutes during drug administration had begun. Red blood cells were separated from plasma and the plasma was analyzed for the presence of diazepam using an assay based on gas chromatography/mass spectrometry using stable isotopically labeled internal standards. In some of the patients, there was a measurable concentration of diazepam in uterine capillary blood following cervical administration, and some patients had greater than a ten-fold higher concentration in uterine blood than peripheral blood. The studies serve as a starting point for the development of delivery systems for other drugs, especially toxic anti-cancer drugs, delivered directly through the cervix and to the uterus. The results indicate that it is possible to deliver a drug locally to the cervix through a transdermal process and observe blood concentrations that are higher than those from peripheral blood. 


\section{List of Abbreviations}

\begin{tabular}{|c|c|}
\hline $\mathrm{amu}$ & atomic mass unit \\
\hline${ }^{\circ} \mathrm{C}$ & degrees Celsius \\
\hline CIN & cervical intraepithelial neoplasia \\
\hline $\mathrm{cm}^{2}$ & square centimeters \\
\hline eI & electron impact \\
\hline $\mathrm{eV}$ & electron volts \\
\hline $\mathrm{g}$ & grams \\
\hline $\mathrm{gc}$ & gas chromatography \\
\hline $\mathrm{gc} / \mathrm{ms}$ & gas chromatography/mass spectrometry \\
\hline HPLC & high pressure liquid chromatography \\
\hline LC/MS-MS & liquid chromatography/tandem mass spectrometry \\
\hline $\mathrm{m}$ & meter \\
\hline MALDI & matrix-assisted laser desorption ionization \\
\hline $\mathrm{MeOH}$ & methanol \\
\hline $\mathrm{mg}$ & milligram \\
\hline $\mathrm{mL}$ & milliliter \\
\hline $\mathrm{M}^{+}$ & molecular ion \\
\hline $\mathrm{mm}$ & millimeter \\
\hline MSD & mass selective detector \\
\hline $\mathrm{m} / \mathrm{z}$ & mass to charge ratio \\
\hline $\mathrm{N}$ & normal \\
\hline ng & nanogram \\
\hline $\mathrm{NaOH}$ & sodium hydroxide \\
\hline $\mathrm{pH}$ & - $\log$ of $\left[\mathrm{H}^{+}\right]$concentration \\
\hline $\mathrm{rpm}$ & revolutions per minutes \\
\hline SIM & selected-ion monitoring \\
\hline TIC & total ion chromatogram \\
\hline TLC & thin layer chromatography \\
\hline $\mathrm{TM}$ & trade mark \\
\hline$\mu g$ & microgram \\
\hline$\mu \mathrm{L}$ & microliter \\
\hline$\mu \mathrm{m}$ & micrometer \\
\hline I & ultraviolet \\
\hline
\end{tabular}




\section{ACKNOWLEDGEMENTS}

I would like to thank Dr. Callery for his guidance and encouragement. I have learned so much in a short amount of time about science and the way that things work. I would like to thank Dr. Tracy and Dr. King for serving on my committee. Paul Kramer, M.D. and Andrew P. Soisson, M.D. did a tremendous amount of work for the study and I am forever grateful. I am thankful for all the help provided by everyone in the Basic Pharmaceutical Sciences department (Blanche Rybeck, Penny Dailey, and so many others). Lastly, I want to thank my family and friends for supporting and believing in me. 


\section{TABLE OF CONTENTS}

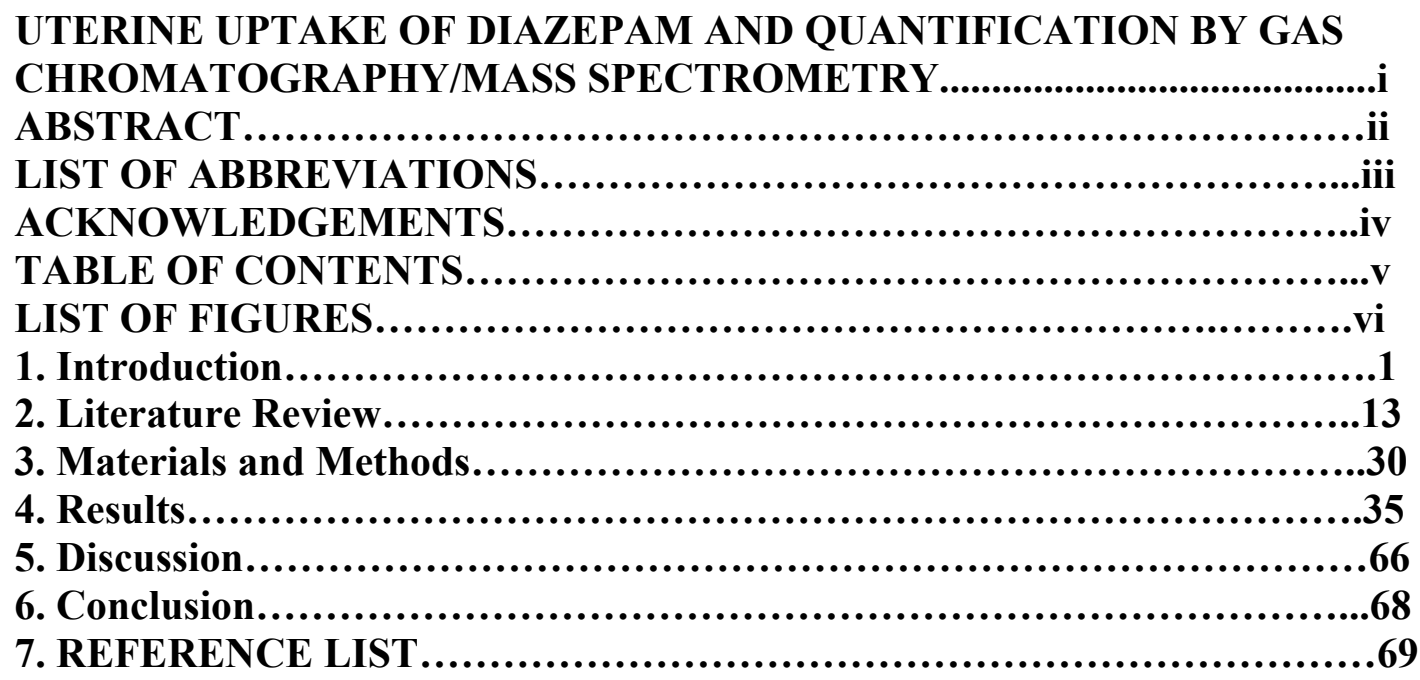




\section{LIST OF FIGURES}

\section{Chapter One}

Figure 1. Drugs given using a transdermal patch..................................

Figure 2. The CerviPrep ${ }^{\mathrm{TM}}$ drug delivery device..............................

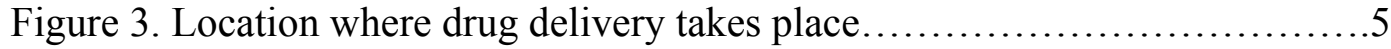

Figure 4. Structure and mass spectrum of diazepam..........................6

Figure 5. Clinically relevant benzodiazepines................................. 8

Figure 6. Electron impact ionization..................................... 10

\section{Chapter Two}

Figure 2.1. The skin's three layers........................................... 14

Figure 2.2. Overview of the female reproductive organs........................ 17

Figure 2.3. Arteries of the female reproductive system......................... 18

Figure 2.4. Benzodiazepines analyzed by GC/MS ..........................21

Figure 2.5. Structure and mass spectrum of diazepam..........................23

Figure 2.6. Additional benzodiazepines analyzed by GC/MS .....................24

Figure 2.7. The chemical structure of 5-fluorouracil.........................26

\section{Chapter Three}

Figure 3.0. Schematic of plasma extraction procedure ..........................32

\section{Chapter Four}

Figure 4.0. A typical standard curve for diazepam................................35

Figure 4.1. Chromatogram and mass spectrum of deuterated diazepam...............36

Figure 4.2. Chromatogram and mass spectrum of diazepam.........................37

Figure 4.3. An ESI spectrum of deuterated diazepam.............................. 38

Figure 4.5. D6 peripheral plasma ............................................ 40

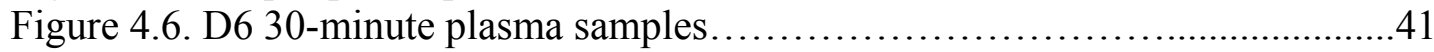

Figure 4.7. D7 peripheral plasma...............................................43

Figure 4.8. D7 30-minute plasma samples......................................44

Figure 4.9. D8 peripheral plasma ............................................. 45

Figure 4.10. D8 30-minute plasma samples..................................46

Figure 4.11. D9 peripheral plasma............................................. 47

Figure 4.12. D9 30-minute plasma samples................................... 48

Figure 4.13. D10 peripheral plasma.............................................49

Figure 4.14. D10 30-minute plasma samples..................................50

Figure 4.15. D11 peripheral plasma.........................................52

Figure 4.16. D11 30-minute plasma samples...................................53 
Figure 4.17. D12 peripheral plasma........................................ 54

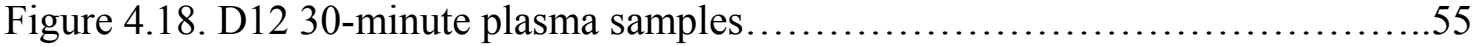

Figure 4.19. D13 peripheral plasma............................................ 56

Figure 4.20. D13 30-minute plasma samples..................................57

Figure 4.21. D15 30-minute plasma samples.................................58

Figure 4.22. D16 30-minute plasma samples..................................59

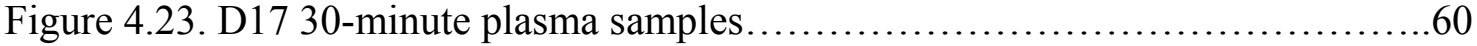

Figure 4.24. D18 peripheral plasma.............................................61

Figure 4.25. D18 30-minute plasma samples.................................62

Figure 4.26. D19 peripheral plasma...........................................63

Figure 4.27. D19 30-minute plasma samples.................................64

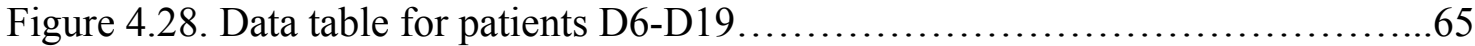




\section{Chapter One}

\section{Introduction}

Transdermal delivery of drugs is not a new concept. Since the early 1980's, adhesive patches containing drug reservoirs and semi-permeable membranes have been used to deliver drugs through the skin. Scopolamine, nitroglycerine, clonidine, nicotine, estradiol, and testosterone have been administered by transdermal patch delivery systems (figure 1). Transdermal delivery provides a slow and steady release of drugs into the bloodstream and avoids first pass metabolism by the liver [1].

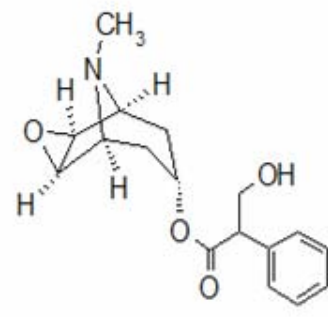

Scopolamine<smiles>O=[N+]([O-])OCC(CO[N+](=O)[O-])O[N+](=O)[O-]</smiles>

Nitroglycerine

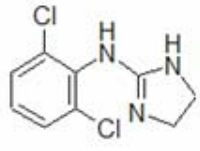

Clonidine

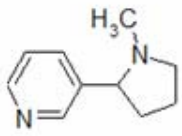

Nicotine

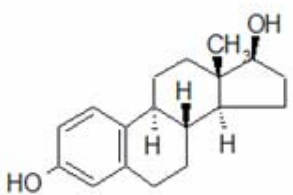

Estradiol

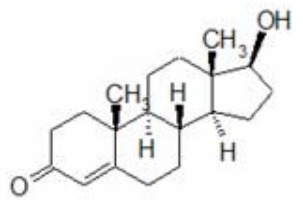

Testosterone

Figure 1. Drugs given by using the transdermal patch [1] 
Transdermal delivery of drugs when applied directly to the cervix is a relatively new concept. A device has been patented (CerviPrep ${ }^{\mathrm{TM}}$ ) that can be used in the delivery of drugs in a gel form and applied directly to the cervix (figures 2 and 3). The device looks much like a syringe with a rounded cup on the tip to serve as a reservoir for the gel. The cup is in close contact with the cervix while the plunger is depressed and the drug enters the reservoir. KY Jelly ${ }^{\mathrm{TM}}$ was chosen as the matrix because it would contain the drug and hold it in place until the more lipophilic cervical tissue absorbed the drug. The drug is absorbed in a mechanism similar to when using a transdermal patch and the lipophilic drug diffuses through the skin. In a study by Woolfson and coworkers, a bioadhesive patch containing 5-fluorouracil was applied to excised cervical tissue and penetration exceeded $10 \mathrm{~mm}$ below the surface when using liquid scintillation spectrometry for measurement [4].

\section{Choice of Model Compound}

Diazepam is a benzodiazepine and was chosen for this study because it is lipophilic, neutral, and generally well-accepted by most of the population. The drug was used only to prove that absorption takes place by applying a drug in a gel form directly to the cervix and that a measurable quantity would be found in plasma samples from the uterine vein and uterine capillary. The molecular weight of diazepam is $284 \mathrm{amu}$ and the ${ }^{2} \mathrm{H}_{5}$ diazepam weighs $289 \mathrm{amu}$. Using electrospray adds one proton $\left(\mathrm{H}^{+}\right)$therefore the

spectrum for the ${ }^{2} \mathrm{H}_{5}$-diazepam will have a base peak of $290 \mathrm{amu}$. It is evident that ${ }^{2} \mathrm{H}_{5}$ diazepam contains a chlorine atom by the presence of a peak 2 units greater (292) and one-third the height of the 290 base peak. For quantification purposes, our GC/MS data was collected in selected ion monitoring (SIM) mode where the mass spectrometer was 
scanning for only a few ions and thus the sensitivity is increased. On occasion, full-scan spectra were obtained and compared to a search library to verify that diazepam was our compound. The most intense ions for diazepam are 256 (100\%), 283 (96\%), and 284 (75\%) (figure 4). 


\section{CerviPrep $^{\mathrm{TM}}$}

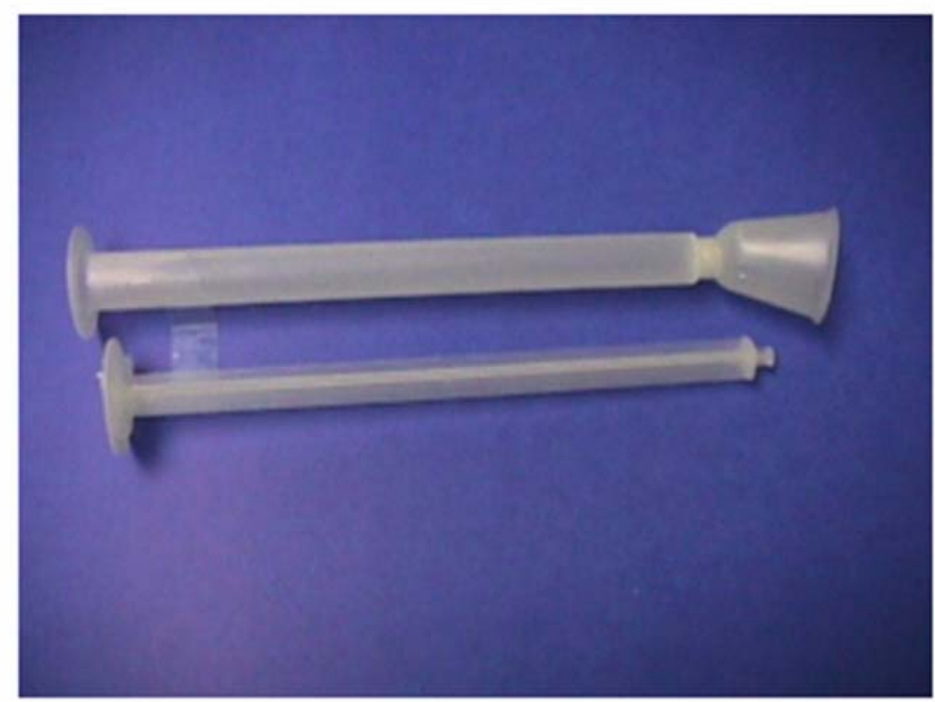

Figure 2 The CerviPrep ${ }^{T M}$ drug delivery device. 
Figure 3

The CerviPrep ${ }^{\mathrm{TM}}$ device allows for direct

application of the drug of interest to the cervix. The geometry of the cup at the end of the syringe was designed to be in close contact with the cervix during drug administration.

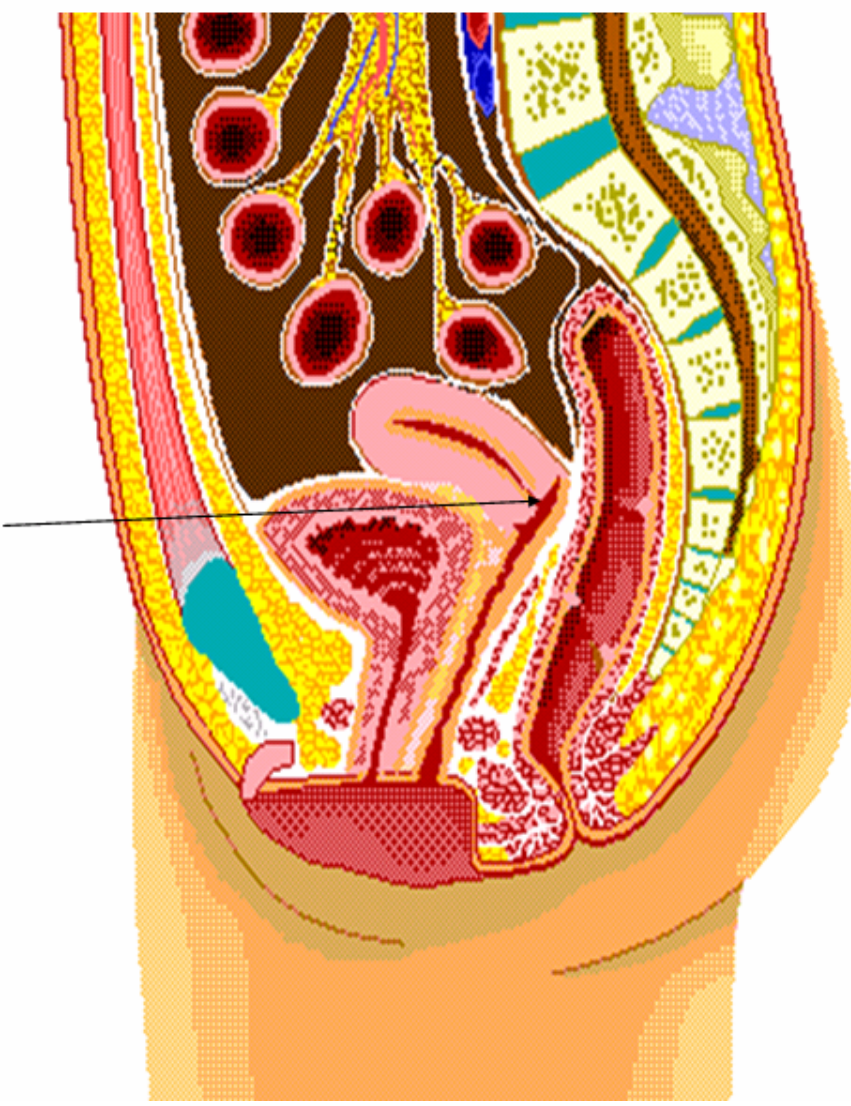

Diagram adapted from www.innerbody.com. 


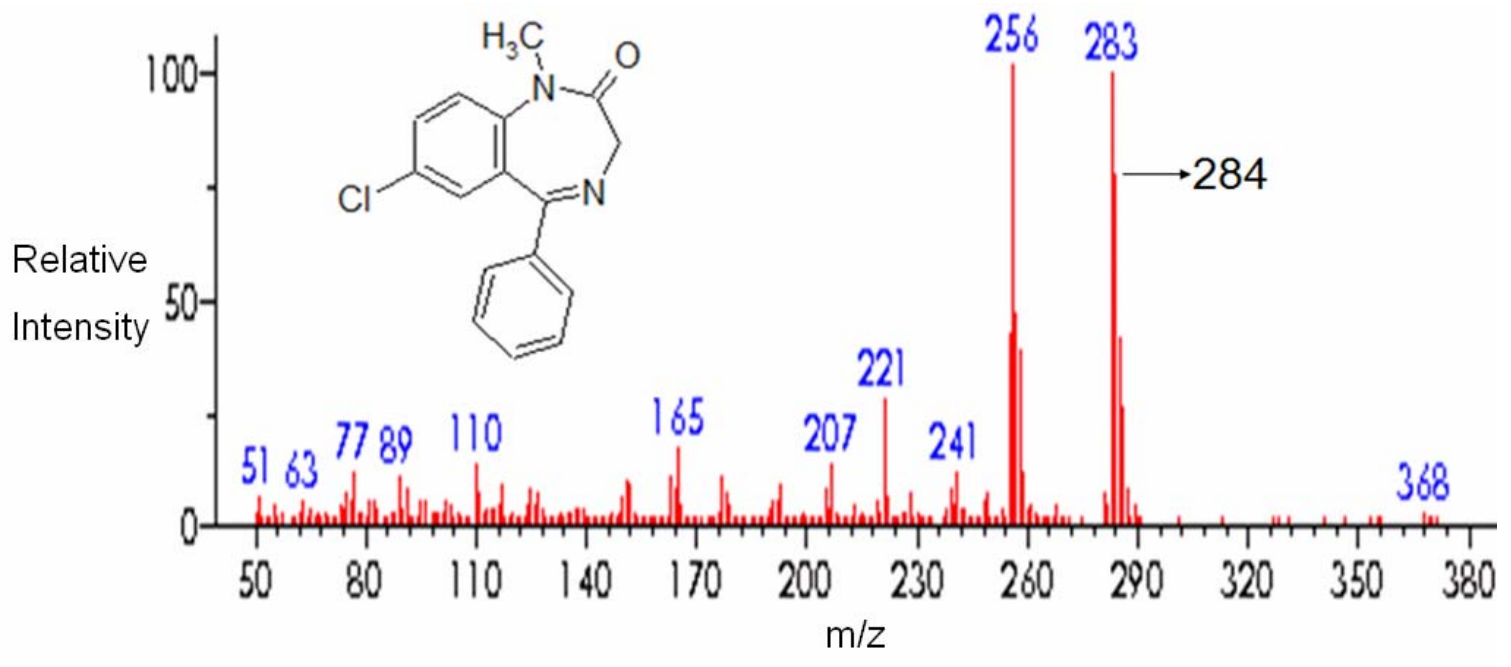

$$
\begin{aligned}
& M^{+.}=284 \\
& (M-H)^{+}=283 \\
& (M-C O)^{+}=256
\end{aligned}
$$

Figure 4 Structure and mass spectrum of diazepam. 
Benzodiazepines (figure 5) are prescribed frequently as anxiolytics, sedative hypnotics, anticonvulsants, and muscle relaxants. They have been used clinically for over 30 years and have recently gained attention as drugs of abuse and used to commit crimes by giving a victim a dose that causes them to blackout. Forensic analysis of these drugs involves methods such as thin-layer chromatography (TLC), gas chromatography (GC), and high performance liquid chromatography (HPLC). These methods identify compounds based on their retention times. Problems arise when two or more compounds elute at the same time and their peaks overlap. More recently, methods have been developed using gas chromatography/mass spectrometry (GC/MS) to identify benzodiazepines by their retention times and by their characteristic ions generated by electron impact (EI) ionization. LC/MS-MS methods have been developed that are very sensitive and utilize MS-MS to obtain structural information about the benzodiazepines. In a study by Kronstrand and coworkers [11], hair samples of psychiatric patients were analyzed and the calibration range for diazepam, nordiazepam, and oxazepam was $0.125-5 \mathrm{ng} / \mathrm{mg}$ of hair $[2,11]$. 


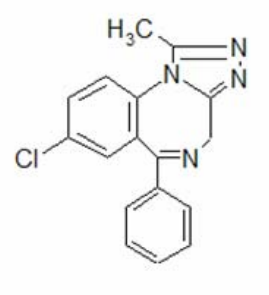

Alprazolam

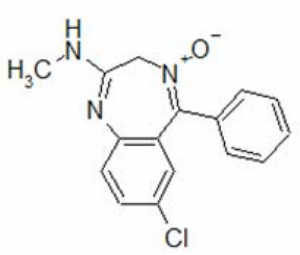

Chlordiazepoxide

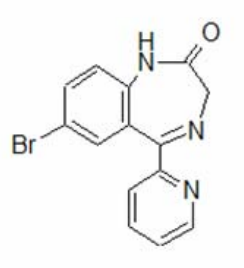

Bromazepam

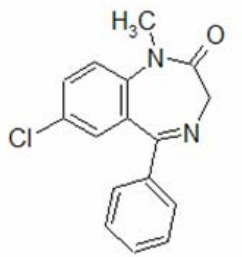

Diazepam

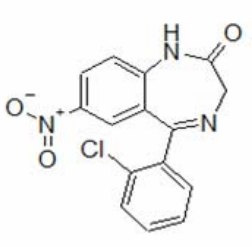

Clonazepam

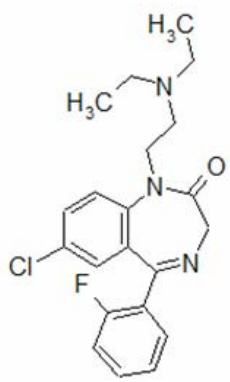

Flurazepam

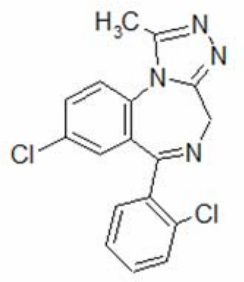

Triazolam<smiles>Oc1ccc2c(c1)C(c1ccccc1Cl)=NC(O)C2O</smiles>

Lorazepam

Figure 5 Examples of clinically relevant benzodiazepines 
The history of mass spectrometry begins with Sir J. J. Thomson of the Cavendish Laboratory of the University of Cambridge, who studied electrical discharges in gases and thus led to the discovery of the electron in 1897 . In the early 20 th century, Thomson went on to construct the first mass spectrometer for the determination of mass-to-charge ratios of ions. In the early stages of mass spectrometry, gases and simple organic molecules were analyzed. More recently, it has been used to study drugs and their metabolites, trace chemicals found at crime scenes, and enzymes and other proteins from biological matrices [11]. The technology associated with mass spectrometry is constantly evolving. Electron impact (EI) ionization, in which gases are passed through an electron beam, was the most common way to ionize compounds of interest (figure 6). Chemical ionization (CI) uses ion-molecule reactions in the gas phase to produce ions from the sample molecule. The process of chemical ionization is initiated with a reagent gas, such as methane, isobutane, or ammonia, which is initially ionized by electron impact. High gas pressure in the ionization source results in the propagation of ion-molecule reactions between the reagent gas ions and reagent gas neutrals. Some of these ions can react with the analyte molecules to produce ions. Chemical ionization can sometimes offer greater sensitivity and for this reason it is commonly used in forensic applications $[15,16]$. Many mass 


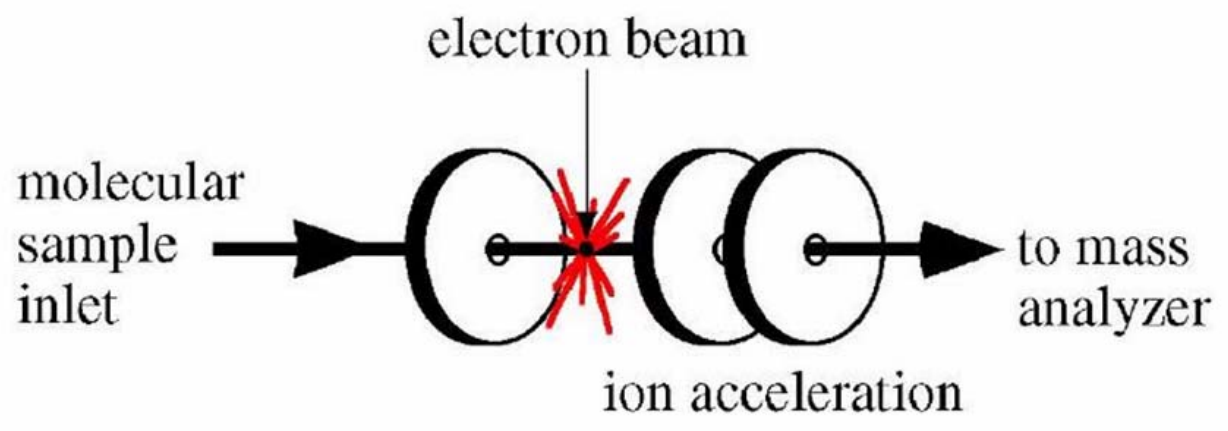

Figure 6 Electron impact (El) ionization is used with GC/MS [3].

Diagram adapted from

http://masspec.scripps.edu/information/history/ 
spectrometers today utilize electrospray where a liquid sample passes through an electrically charged nozzle, is nebulized, and then enters a heated capillary on its way to the mass detector. Matrix-assisted laser desorption ionization (MALDI) uses a UV-light absorbing matrix mixed with the sample of interest to form a precipitate on a stainless steel plate. A UV-laser is fired at the plate and the sample receives enough energy to become ionized, pulled through a vacuum chamber, and is focused electrically until it reaches the mass detector. This technique is used mostly to analyze proteins and other biomolecules and is becoming quite common. Mass spectrometry is used in quantitative studies because of its high sensitivity. A trace amount of a chemical can be detected by using an effective method to extract the chemical from its matrix and analyze it with mass spectrometry. For many compounds, there is very good linearity as the concentration of the analyte increases. Standard curves are constructed by adding a fixed amount of a standard to increasing concentrations of a compound and plotting the relationship on an XY plot. It is common to see correlation coefficients above 0.995 for most analytes in the concentration range of one to 500 nanograms per $\mathrm{mL}$ by GC/MS. Internal standards are used in analytical chemistry to verify that the instrument and all associated parameters are functioning properly and consistently and the ratio of concentration/signal response is used along with the signal response of an unknown to calculate its concentration. Stable isotopically-labeled analogs of certain compounds are commonly used as internal standards. GC/MS in mass spectrometric analysis can distinguish between two compounds that differ in mass by only one atomic mass unit (amu). With this in mind, analogs of certain compounds are synthesized using deuterium, which weighs two amu rather than one amu as is the case for hydrogen, allowing for the 
detection of the analyte in the presence of internal standard. The best standards add three or more deuterium atoms to the analyte to avoid confusion by the signal for the ${ }^{13} \mathrm{C}$ isotopomer and that of the internal standard. Deuterium labeled analogs have almost the same physical properties, such as retention time in gas and liquid chromatography as their non-labeled counterparts. Examples of isotopically labeled internal standards used in quantitative $\mathrm{GC} / \mathrm{MS}$ studies include $\left[{ }^{13} \mathrm{C}_{12}\right]$-polychlorinated biphenyls, ${ }^{14} \mathrm{C}$-arachidonic acid, and $\left[6,6-{ }^{2} \mathrm{H}_{2}\right]$-ascorbic acid [6,12-14]. 


\section{Chapter Two}

\section{Literature Review}

\section{Transdermal Drug Delivery}

Transdermal drug delivery has been well-studied [7]. Numerous compounds have been administered successfully by using a transdermal patch in which the drug diffuses through the skin. After a drug passes through the skin, it enters the general circulation for a systemic effect. The first transdermal patch (called the Transderm Scop) was approved by the Food and Drug Administration in 1979 for the prevention of nausea and vomiting associated with travel, particularly sea-sickness.

Measuring the effectiveness of a transdermal system can involve detection of the drug in blood plasma, measuring excretion of the drug and/or its metabolites in the urine, and patient response at some point after administration. Using transdermal delivery, the blood concentration needed to obtain therapeutic efficacy may be determined by comparative analysis of patient response to drug blood levels. It is preferable if the drug penetrates through the skin to the underlying blood supply without drug buildup in the dermal layers. The skin is comprised of the stratum corneum (the outer-most layer), the living epidermis, and the dermis, which together provide the skin's protection against penetration by external agents (figure 2.1) [7]. 


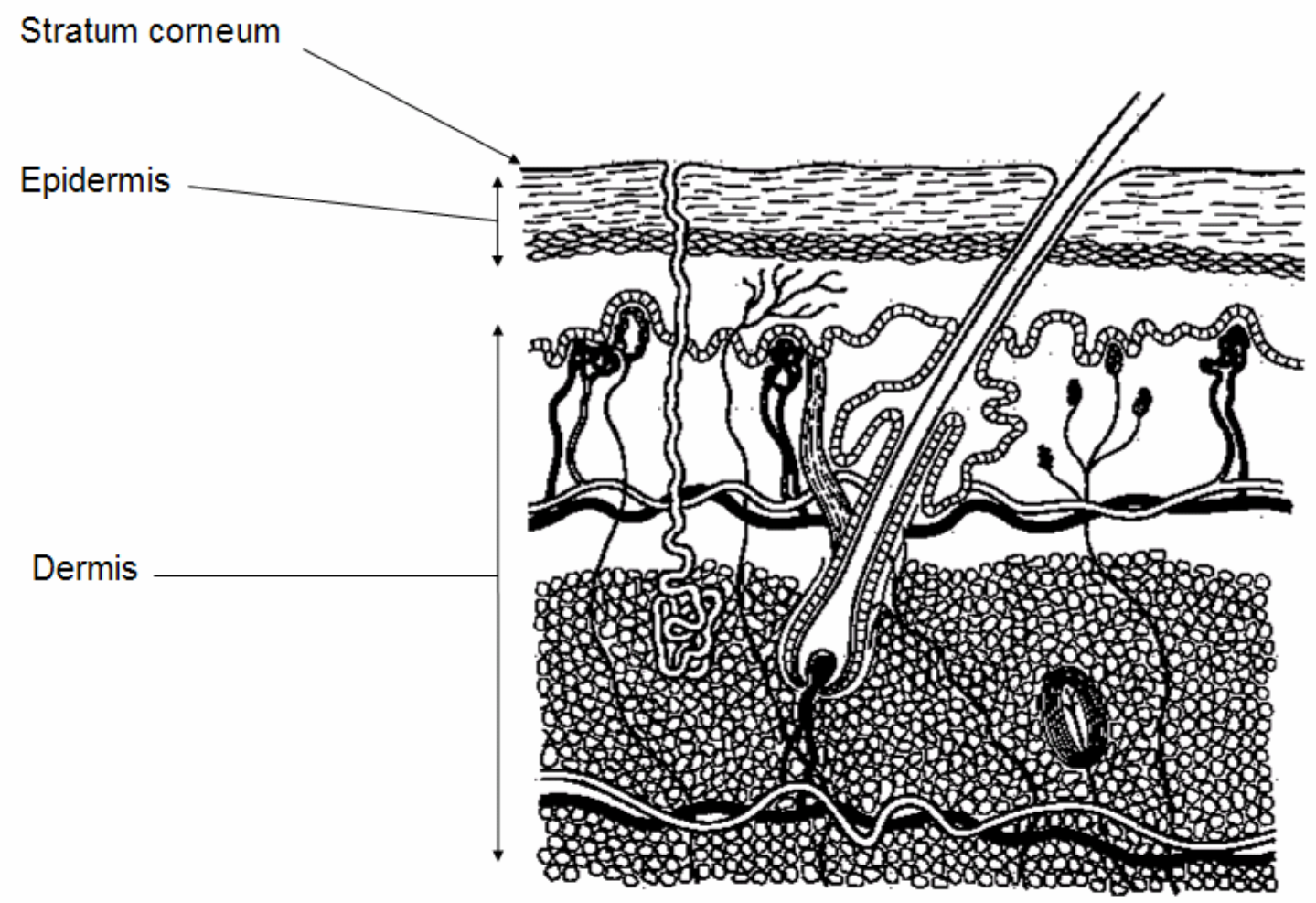

Figure 2.1 The skin's 3 layers [7]

The film that covers the stratum corneum is composed of sebum and sweat, and because of its varied composition and lack of continuity, it is not a significant factor in drug penetration and neither are the hair follicles and sweat and sebaceous gland ducts which comprise only a minor proportion of the skin's surface.

Percutaneous absorption of a drug usually results from direct penetration of the drug through the layer of flat, partially desiccated nonliving tissue. The stratum corneum is composed of roughly $40 \%$ protein (mostly keratin) and $40 \%$ water, with the remaining portion consisting of lipids as triglycerides, free fatty acids, cholesterol, and 
phospholipids. Lipid content is concentrated in the extracellular phase of the stratum corneum and forms essentially a membrane surrounding the cells. A major route of drug penetration is through the intercellular channels and the lipid component is considered to be an important determinant in the first step of drug absorption.

After passing through the stratum corneum, drug molecules may then pass through the deeper epidermal tissues and into the dermis. When the drug enters the vascular dermal layer, it becomes available for absorption into the general circulation. Because the stratum corneum is a keratinized tissue, it behaves as a semipermeable artificial membrane and drugs penetrate by passive diffusion. It is considered to be the major rate-limiting barrier to transdermal drug transport. The majority of the body contains a stratum corneum that has 15-25 layers of flattened corneocytes with an overall thickness of roughly $10 \mu \mathrm{m}$. The rate of drug penetration across this layer depends on the concentration of the drug in the delivery system, its aqueous solubility, and the oil/water partition coefficient between the stratum corneum and the delivery system. Drugs that possess both lipid and aqueous solubility characteristics are good candidates for diffusion through the stratum corneum and the epidermal and dermal layers [7].

\section{Factors Affecting Transdermal Delivery}

Not every drug can be used effectively in a transdermal delivery system. Factors such as the physical and chemical properties of the drug including molecular weight, solubility, partitioning coefficient, $\mathrm{pKa}$, the nature of the carrier-vehicle, and the condition of the skin all affect the success of drug delivery. Generally, the amount of drug absorbed increases as the concentration of the drug substance in the delivery system is increased. More drug is absorbed when the surface area of application is increased. The drug should 
have a greater physicochemical affinity to the skin than to the delivery system in order for the drug to leave the system and penetrate into the skin. Some solubility of the drug in lipid and aqueous media is essential for effective absorption. The aqueous solubility of the drug determines the concentration delivered to the absorption site and the partition coefficient dictates the rate of transport across the absorption site. Drugs penetrate through the skin best when they are unionized. Drugs with molecular weights in the 100 to 800 range and adequate lipid and aqueous solubility can usually permeate skin. The most effective molecular weight for a drug to be used in transdermal delivery is believed to be 400 or less [7].

\section{The Cervix}

The cervix is the narrow, most posterior portion of the uterus. It is conical in shape, with a truncated apex that points downward and backward. It is about one inch long and continuous above with the inferior aspect of the uterine corpus, which is the point of juncture known as the isthmus, an area of moderate constriction (figure 2.2). 
The Uterus, Cervix, and Vagina

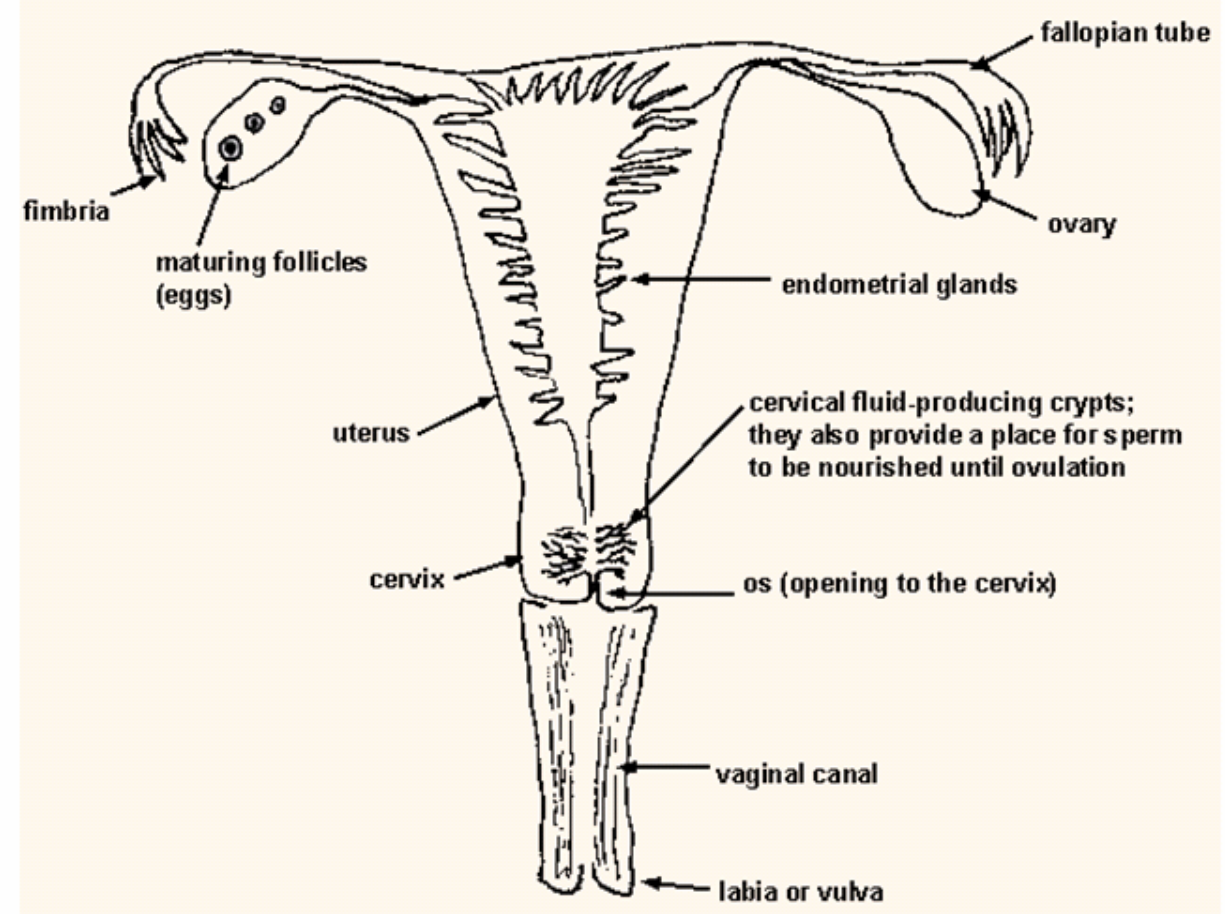

Figure 2.2 Overview of the female reproductive organs (adapted from http://www.fertilityawareness.net/reprofemale. html) 
The vagina is attached obliquely around the center of the cervical periphery, therefore dividing the cervix into two sections, the upper or supravaginal portion and a lower vaginal portion. The cervix enters the vagina at an angle through the anterior vaginal wall, and normally the vaginal portion is in contact with the posterior vaginal wall [8]. The supravaginal part of the cervix is separated anteriorly from the bladder by a layer of endopelvic fascia. Laterally, this same level of the cervix is continuous with the paracervical ligaments and the uterine blood vessels which they contain (figure 2.3).

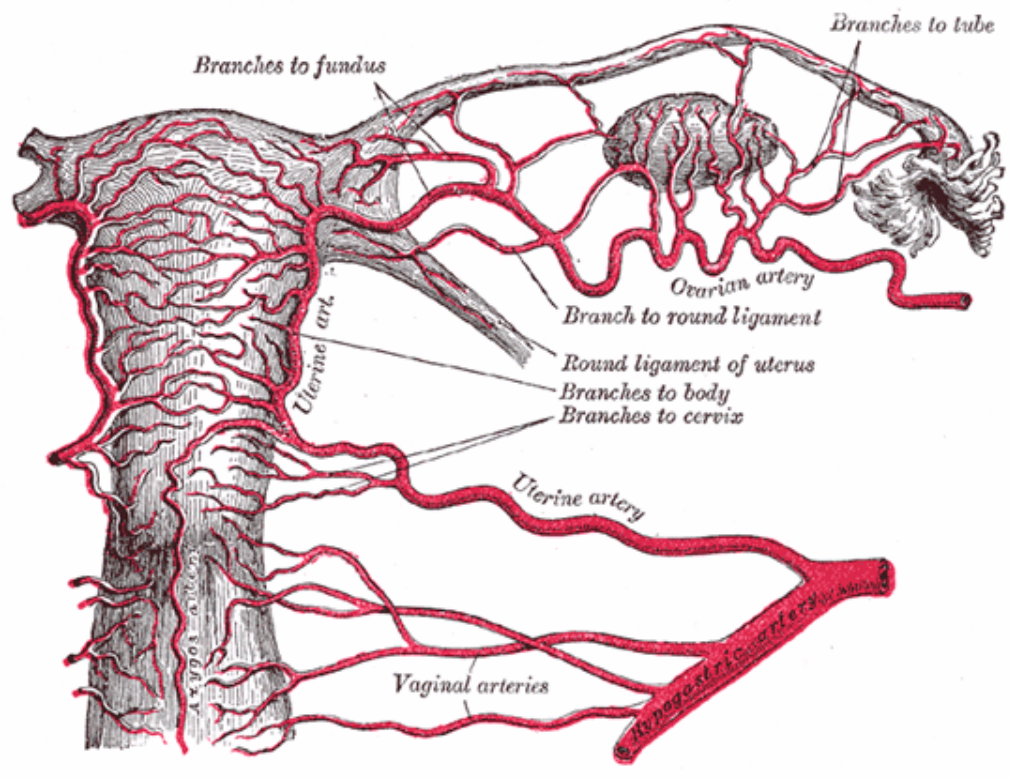

Figure 2.3 Arteries of the female reproductive system as seen from behind (adapted from http://www.yahooligans.com/reference/gray/fig/1170.html) 
Posteriorly, the supravaginal cervix is covered by peritoneum as is reflects off the uterosacral ligaments downward toward the apex of the vagina. The vaginal portion of the cervix protrudes into the upper vagina between the upper and lower fornices as a convex prominence of somewhat elliptical shape. A small aperture, which is round or slit-like in the nullipara, is central to the protrusion and called the external cervical os. This orifice makes the connection between the uterine cavity and the vagina. The external os is encircled by the anterior and posterior lips and they are covered with stratified squamous epithelium. The cervical canal extends from the anatomic external os to the internal os, where it opens into the uterine cavity. It is somewhat fusiform or spindle-shaped and wider in the middle than at either os. Anterior and posterior longitudinal ridges are evident on the walls of the cervical canal. They represent lines of fusion of the müllerian ducts. Fanning out laterally from these ridges is a series of folds (the plicae palmatae) which resemble branches of a tree trunk. Some evidence suggests the presence of drug transporters in cervical tissue and thus the concept cannot be ruled out [8].

\section{Vaginal Drug Absorption}

Many drugs have been administered through delivery from the vagina. Miconazole nitrate, metronidazole, and other compounds have been delivered in a gel or cream and applied to the outer surface and/or inserted into the vagina. Similar to using a transdermal patch, this route of administration avoids first-pass metabolism by the liver. However, the localized blood flow of the organ is of a nature that drugs are taken up quickly and readily enter systemic distribution [8]. 


\section{Quantification of Diazepam by GC/MS}

Measurement of Diazepam in blood plasma using GC/MS has proven to be fast, accurate, and repeatable by researchers over the years $[2,9,10]$. Clinical situations involving pharmacokinetic studies, therapeutic monitoring, dosage regimens, and identification of compounds with forensic significance have led to the development of several methods for quantitation [2]. In a study by Coassolo and coworkers [2], several benzodiazepines were extracted from plasma and quantitated by GC/MS (figure 2.4). The benzodiazepines 

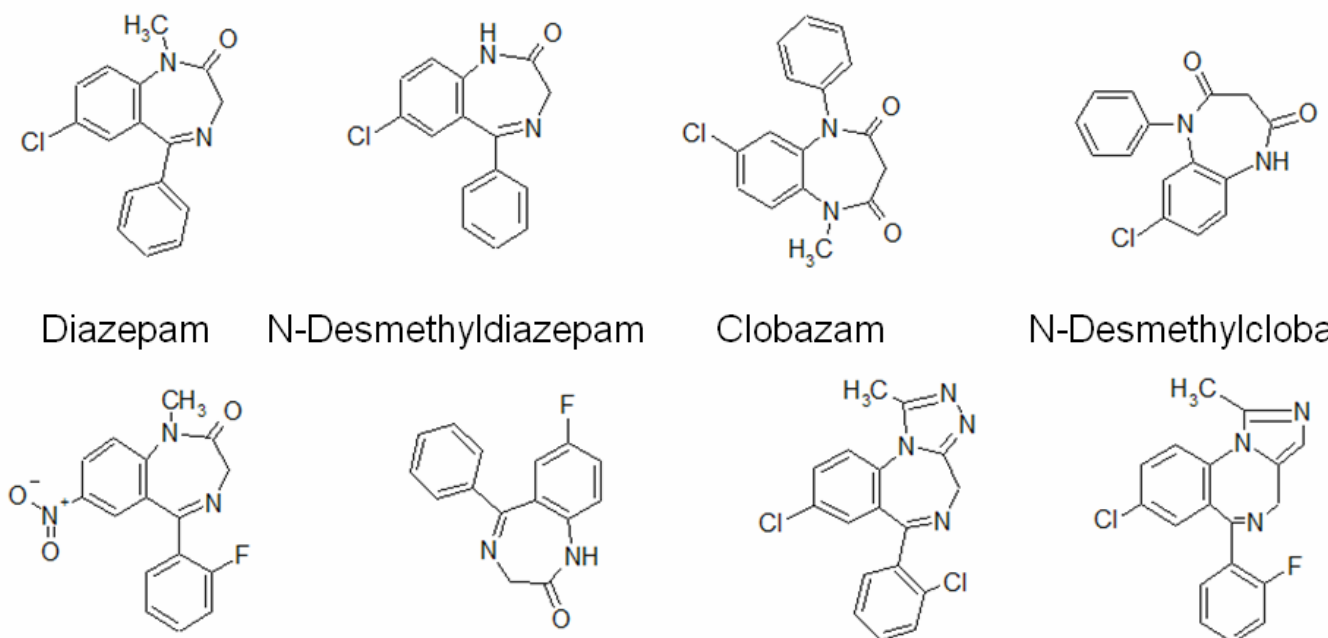

N-Desmethyldiazepam

Clobazam

$\mathrm{N}$-Desmethylclobazam
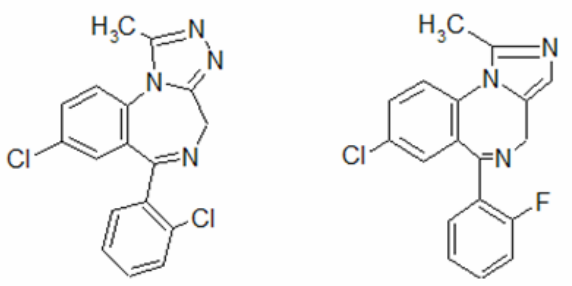

Flunitrazepam N-Desmethylflunitrazepam Triazolam

Midazolam<smiles>O=C1Nc2ccc(Cl)cc2C(c2ccccc2)=NC1O</smiles><smiles>CN1C(=O)C(O)N=C(c2ccccc2)c2cc(Cl)ccc21</smiles><smiles>O=C1Nc2ccc(Cl)cc2C(c2ccccc2Cl)=NC1O</smiles>

Oxazepam

Temazepam Lorazepam

Figure 2.4 Benzodiazepines analyzed by GC/MS 
were extracted from plasma via a liquid-liquid extraction with butyl acetate at a $\mathrm{pH}$ of 9.0. The analysis was performed on a compact mass-selective detector operating in the electron-impact (EI) mode. Samples of 1-3 $\mu \mathrm{L}$ were injected into the GC/MS with the inlet temperature set at $250{ }^{\circ} \mathrm{C}$, helium as the carrier gas, and the oven temperature went from 70 to $300{ }^{\circ} \mathrm{C}$ at a ramp of $20^{\circ} \mathrm{C}$ per minute. The compounds were ionized at $70 \mathrm{eV}$ when they entered the mass-selective detector. Identification of the compounds was performed by either direct comparison of the observed mass spectra with reference spectra or by the relative intensities of the most intense and characteristic ions collected in the selected-ion monitoring (SIM) mode. Certain benzodiazepines were used as internal standards for quantitation based on the fact that their retention times were significantly different than that of the analyte of interest to avoid co-elution of peaks. Intra-assay precision and accuracy were better than 5-6 percent, linearity was satisfactory up to $2 \mu \mathrm{g} / \mathrm{mL}$, and the detection limit was $1-5 \mathrm{ng} / \mathrm{mL}$ for most benzodiazepines. Diazepam was chosen as the internal standard when measuring flunitrazepam and $N$ desmethylflunitrazepam in plasma. Concentrations of diazepam added ranged from 2.1 to $21 \mathrm{ng} / \mathrm{mL}, 3.9$ to $39 \mathrm{ng} / \mathrm{mL}$, and 4.2 to $42 \mathrm{ng} / \mathrm{mL}$ and their respective correlation coefficients were $0.998,0.990$, and 0.998 . The base peak for diazepam was $m / z 256$, the second most intense ion was $m / z 283$, and the molecular ion $\left(\mathrm{M}^{+}\right)$with $m / z$ of 284 was the third most intense ion (figure 2.5) [2]. 


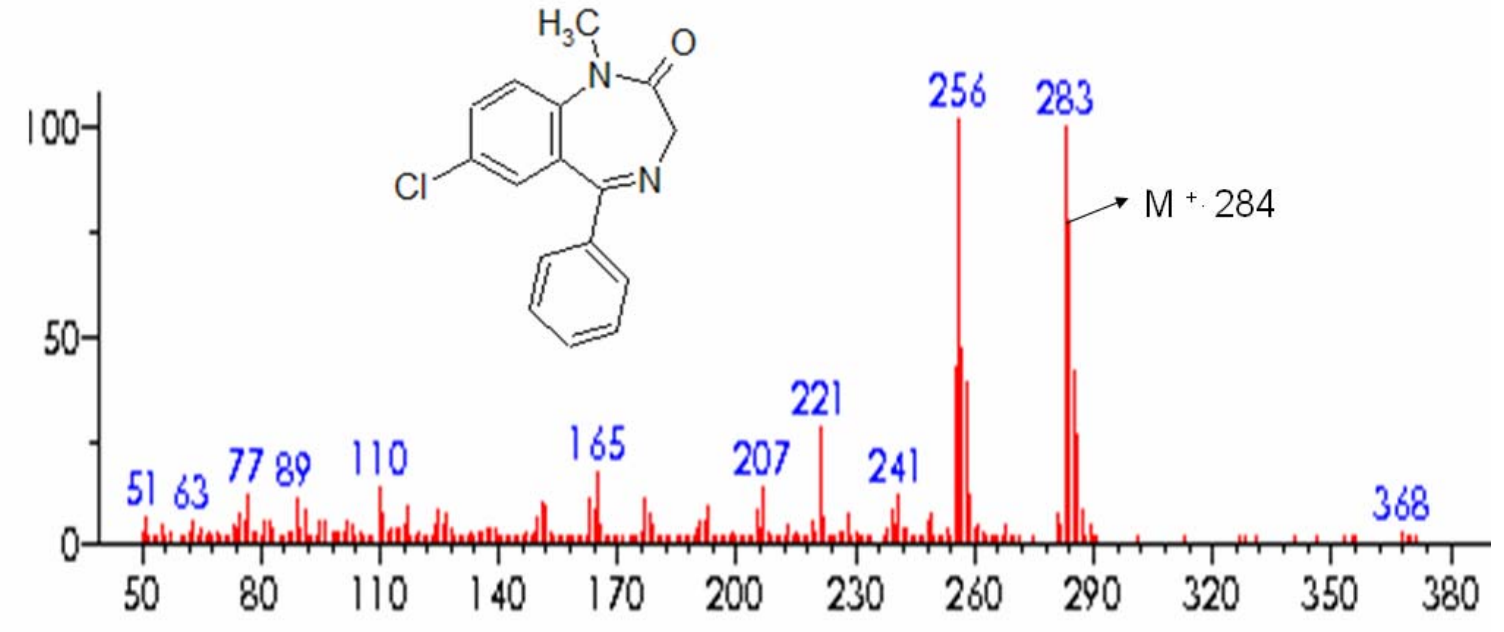

Figure 2.5 Structure and mass spectrum of diazepam 
In another study by Inoue and coworkers [9], several benzodiazepines were extracted from whole blood using a solid-phase extraction and quantification was performed by GC/MS. Whole blood was spiked with various benzodiazepines and the extraction was performed using an Oasis ${ }^{\mathrm{TM}}$ HLB solid-phase extraction cartridge that contains a copolymer designed to have a hydrophilic-lipophilic balance (figure 2.6). Nineteen<smiles>CN1C(=O)CCN=C(c2ccccc2F)c2cc(Cl)ccc21</smiles>

Fludiazepam<smiles>CN1C(=O)CN=C(c2ccccc2)c2cc([N+](=O)[O-])ccc21</smiles>

Nimetazepam

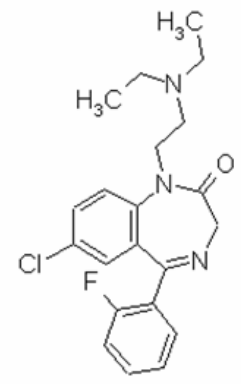

Flurazepam<smiles>O=C1Nc2ccc(Cl)cc2C2(c3ccccc3Cl)OCCN2CCO1</smiles>

Cloxazolam<smiles>CN1CCC=NC(c2ccccc2)c2cc(Cl)ccc21</smiles>

Medazepam<smiles>CC1COC2(c3ccccc3Cl)CN1CC(=O)Nc1ccc(Cl)cc12</smiles>

Mexazolam<smiles>O=C1CN=C(c2ccccc2)c2cc([N+](=O)[O-])ccc2N1</smiles>

Nitrazepam<smiles>O=C1CN2CCOC2(c2ccccc2F)c2cc(Br)ccc2N1</smiles>

Haloxazolam

Figure 2.6 Some of the additional benzodiazepines 
benzodiazepines and two thienodiazepines were identified using a combination of selected ion monitoring (SIM) and total ion chromatograms (TIC) on a GC/MS. Calibration curves for the various compounds were constructed using fludiazepam as an internal standard and excellent linearity was observed over the concentration range of 5$500 \mathrm{ng} / \mathrm{mL}$ in blood with correlation coefficients greater than 0.995 . The limit of detection ranged from 0.2 to $20 \mathrm{ng} / \mathrm{mL}$ in blood. The extraction procedure involved adding known concentrations of the compounds in methanol to $1 \mathrm{~mL}$ of blood and mixing with $4 \mathrm{~mL}$ of distilled water. The mixture was centrifuged and the supernatant was mixed with $0.05 \mathrm{M}$ phosphate buffer at $\mathrm{pH}$ 7.0.

Oasis ${ }^{\mathrm{TM}}$ HLB cartridges were pretreated with methylene chloride, methanol, and distilled water and then the sample solution was loaded into the cartridge. $3 \mathrm{~mL}$ of distilled water was used to wash the cartridge and the compounds were then eluted with 5 $\mathrm{mL}$ of methylene chloride. The eluates were centrifuged and the remaining aqueous layer was discarded and the organic layer was evaporated under nitrogen. The residues were reconstituted in methanol and fludiazepam was added as the internal standard. $2 \mu \mathrm{L}$ samples were injected into the $\mathrm{GC} / \mathrm{MS}$ with the injection port set at $280{ }^{\circ} \mathrm{C}$, helium as the carrier gas, the oven temperature went from 60 to $300{ }^{\circ} \mathrm{C}$ at $20^{\circ} \mathrm{C}$ per minute, and the mass spectrometer was used in electron impact (EI) mode with the ionization energy at $70 \mathrm{eV}[9]$.

Diazepam was quantified and gave the following $\mathrm{m} / \mathrm{z}$ ions with their respective intensities: $256(100 \%), 283(96 \%), 284$ (75\%), 221 (44\%), and $286(24 \%)$. The natural ratio of ${ }^{35} \mathrm{Cl}$ and ${ }^{37} \mathrm{Cl}$ (a 3:1 ratio) was evident in the 284 and 286 ions. Linearity of diazepam was excellent over the range of $5-500 \mathrm{ng} / \mathrm{mL}$ in blood and the correlation 
coefficient was greater than 0.995 . The limit of detection for diazepam was $1 \mathrm{ng} / \mathrm{mL}$ and the method proved to be simple and sensitive for measuring benzodiazepines and thienodiazepines [9].

\section{Other Studies Involving Transdermal Delivery to the Cervix}

In a study by Woolfson and coworkers [4], bioadhesive patches containing tritiumlabeled 5-fluorouracil were applied to excised, healthy cervical tissue from hysterectomy patients and drug diffusion was measured by liquid scintillation spectrometry (figure 2.7).<smiles>O=c1[nH]cc(F)c(=O)[nH]1</smiles>

Figure 2.7 The structure of 5-fluorouracil. The radioactive, ${ }^{3} \mathrm{H}$-labeled 5 fluorouracil has a similar structure except one of the hydrogen atoms is replaced with an ${ }^{3} \mathrm{H}$ (tritium). 
Pre-cancerous dysplastic lesions can often occur in cervical tissue. The lesions have been defined as cervical intraepithelial neoplasia (CIN) and they range from mild (CIN I) to severe dysplasia (CIN III). Cervical intraepithelial dysplasia is initially a noninvasive condition and can be identified by smear screening and colposcopy. When cases of nonregressing CIN are discovered, treatment usually involves ablative or excisional surgical techniques. Surgery can be very expensive and there is often some resulting damage to the structure of the cervix. Alternative methods to treat CIN are therefore being investigated. It has been shown that lesions can occur not only at the squamocolumnar junction, but also in the glandular tissue and cervical crypts. The depth required for drug diffusion in order to reach theses structures is at least $4 \mathrm{~mm}$ below the surface of application of the cervix. Patches containing 3.5, 10, and $20 \mathrm{mg}$ of tritium-labeled 5fluorouracil were applied to excised cervical tissue cut into slabs $1 \mathrm{~cm}^{2}$ across the epithelial face and approximately $10 \mathrm{~mm}$ deep. The tissue was supported on a stainless steel filter grid placed across a reservoir filled with sterile phosphate buffered saline $(\mathrm{pH}$ 7.2) with the volume sufficient to bring the solution up to the grid and expel traces of air. The time that the tissue was exposed to the patches was recorded and the tissue was flashfrozen by exposing it above a liquid nitrogen atmosphere. The tissue was then cut into slices $50 \mu \mathrm{m}$ thick, added to an appropriate scintillation cocktail, and the amount of drug present in the slices determined by liquid scintillation counting. Patches with different concentrations of the drug were applied to the tissue for 4, 8, 12, 18, and 24 hours and as expected, the $20 \mathrm{mg}$ patch produced the highest concentrations at the various tissue depths. After the shortest application time of 4 hours, 5-fluorouracil was detected in cervical tissue down to a depth of at least $5.5 \mathrm{~mm}$ (where it can reach the glandular tissue 
and cervical crypts). For the intermediate time intervals, the maximum diffusion profile was observed with little variation at the 8,12 , and 18 hour applications. The 10 and 20 mg patches showed similar diffusion patterns with the distribution being linear and anomalies observed only in the tissue layers close to the epithelial surface. It is likely that remnants of the patch were collected on the first slice of tissue sample and this led to the unusually high concentration observed. The results indicate that the penetration of 5fluorouracil was rapid and extended into the deepest tissue layers. The drug was detected in all reservoirs for the various time periods and all patch doses. This indicates that drug penetration reached a minimum depth of $10 \mathrm{~mm}$ below the surface of application. At the critical depth of $5.5 \mathrm{~mm}, 5$-fluorouracil concentrations exceeded $0.25 \mu \mathrm{g}$ per $\mathrm{mg}$ of tissue using the $3.5 \mathrm{mg}$ patch concentration. The $10 \mathrm{mg}$ patch gave a concentration of approximately $0.75 \mu \mathrm{g}$ per $\mathrm{mg}$ of tissue and the $20 \mathrm{mg}$ patch gave $1.0 \mu \mathrm{g}$ per $\mathrm{mg}$ of tissue. The concentration observed with the $20 \mathrm{mg}$ patch was roughly 2,000 times in excess of the cytotoxic concentration of 5-fluorouracil determined in vitro against HeLa cells. The results suggest that the bioadhesive patch could be effective against malignant cells in cervical tissue [4].

In another study by Woolfson and coworkers [5], a similar approach was employed by delivering tritium-labeled 5-fluorouracil to excised cervical tissue via a bioadhesive patch. This study used only the $20 \mathrm{mg}$ patch and quantification was performed using autoradiographic imaging. The patches were applied for 4 and 24-hour time periods and the results were similar to the previous study in that the 4-hour application was found to be insufficient to achieve high drug concentration throughout the upper half of the tissue specimen ( $5 \mathrm{~mm}$ below the epithelial surface). However, the 
24-hour application showed that drug distribution was sufficient to expose potential cervical intraepithelial neoplasia (CIN) to cytotoxic levels of 5-fluorouracil. The autoradiographs showed evidence of areas of locally high drug concentration which could be aqueous-filled pores that are known to be present in the cervix. 5-Fluorouracil is relatively water soluble and thus diffusion through aqueous pores could have a significant role in drug diffusion through the cervix. 


\section{Chapter Three}

\section{Materials and Methods}

\section{Materials}

Diazepam was purchased from Sigma Chemical Company (St. Louis, MO). Deuterated ${ }^{2} \mathrm{H}_{5}$-diazepam was purchased from Cambridge Isotope Laboratories (Andover, MA). KY Jelly ${ }^{\mathrm{TM}}$ was obtained locally. Diazepam $(5 \mathrm{mg} / 5 \mathrm{~g})$ was formulated in KY Jelly ${ }^{\mathrm{TM}}$ by the Pharmacy Department of Ruby Hospital, Morgantown, WV and stored under refrigeration. Absolute ethanol was purchased from Mallinckrodt Baker (Paris, Kentucky). All other chemicals were obtained from Aldrich Chemical Company (Milwaukee, WI) and were of the highest purity available.

\section{Patient Information}

No personal information about the subjects that volunteered for the study was collected at any time. The patients were referred to by the letter D and numbers one through 19 (D1-D19).

\section{Preparation of Solutions}

Stock solutions of diazepam and ${ }^{2} \mathrm{H}_{5}$-diazepam were prepared by dissolving accurately weighed $10.0 \mathrm{mg}$ in $10.0 \mathrm{~mL}$ of reagent grade methanol. Subsequent dilutions of 1,10 , $40,100,250$, and $500 \mathrm{ng} / \mathrm{mL}$ in methanol were made and standard curves were constructed using $40 \mu \mathrm{L}$ of ${ }^{2} \mathrm{H}_{5}$-diazepam ( $1 \mu \mathrm{g} / \mathrm{mL}$ in methanol) added to the various concentrations of diazepam. Control samples of blank plasma were obtained from a local hospital and found to be drug free before use. 


\section{Methods}

Patients undergoing hysterectomy were anesthetized and $5 \mathrm{mg}$ of diazepam in $5 \mathrm{~g}$ of gel was administered using the CerviPrep ${ }^{\mathrm{TM}}$ device. The operation was then begun and blood samples were taken from a peripheral vein at $0,5,10,15$, and 30 minutes during drug administration. Samples were also taken from the uterine vein and uterine capillary bed at 30-45 minutes during drug administration. Blood samples were processed to separate red blood cells from plasma. The plasma sample $(1 \mathrm{~mL})$ was taken and $40 \mu \mathrm{L}$ of ${ }^{2} \mathrm{H}_{5}$-diazepam ( $1 \mu \mathrm{g} / \mathrm{mL}$ in methanol) was added and vortexed for one minute. Sodium hydroxide $(20 \mu \mathrm{L}, 2 \mathrm{~N})$ was added to adjust the $\mathrm{pH}$ of the sample to about 9 and $3 \mathrm{~mL}$ of ethyl acetate were added and vortexed for one minute. Samples were then placed in a Dynac $^{\mathrm{TM}}$ centrifuge at $10,000 \mathrm{rpm}$ for 5 minutes and the ethyl acetate layer was removed by micropipette. The liquid was then evaporated in a $15 \mathrm{~mL}$ test tube on a heat block at $80{ }^{\circ} \mathrm{C}$ under a gentle stream of nitrogen. The residues were reconstituted with $40 \mu \mathrm{L}$ of

ethanol, placed in National Scientific ${ }^{\mathrm{TM}}$ GC/MS auto sampler vials, and $2 \mu \mathrm{L}$ was injected into the GC/MS (schematic 3.0). 


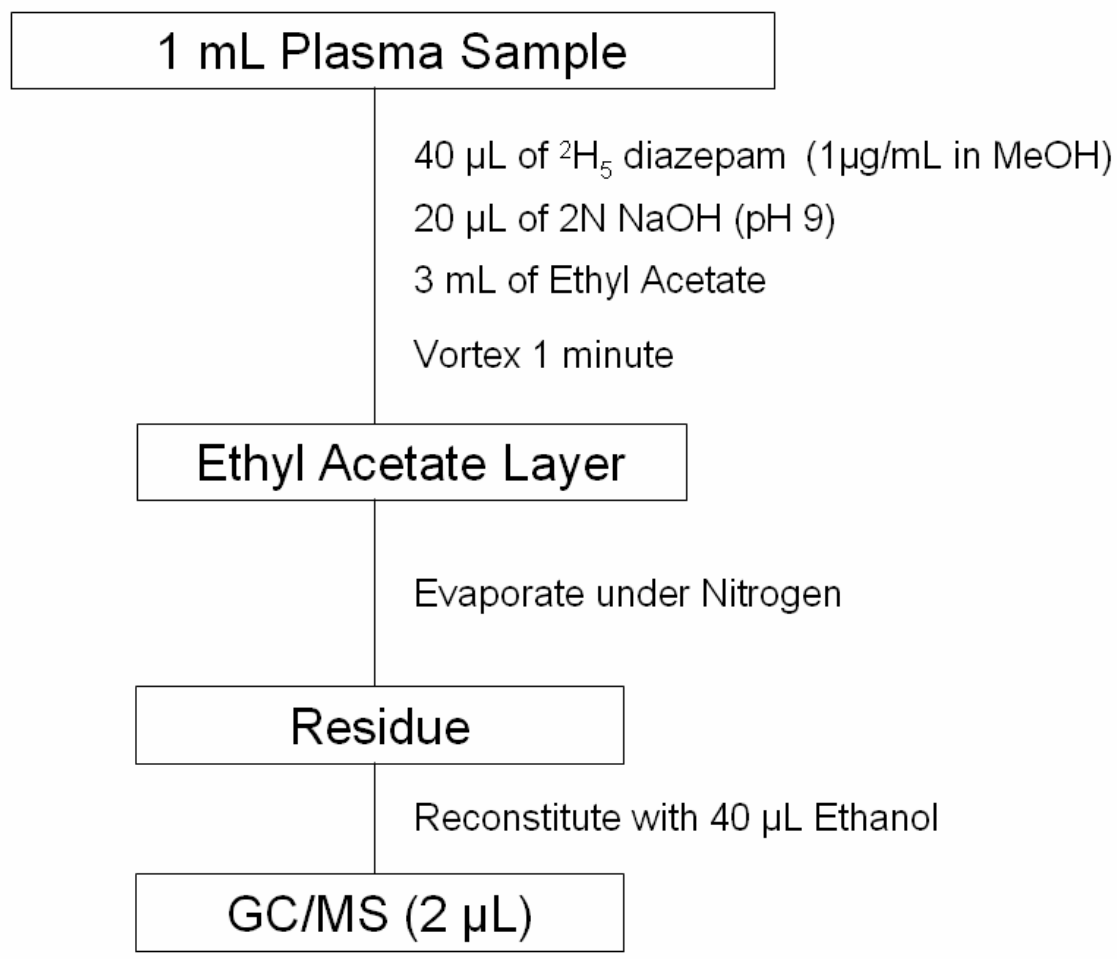

Figure 3.0 Schematic of extraction procedure 
The method adapted from a validated method by Choi [10] and the limit of detection for diazepam was $0.5 \mathrm{ng} / \mathrm{mL}$, the assay was sensitive to $1 \mathrm{ng} / \mathrm{mL}$ and linear to $500 \mathrm{ng} / \mathrm{mL}$ with a correlation coefficient of 0.997 , and the recovery was 93.4 percent.

\section{Instrumentation}

The samples were analyzed by an Agilent MSD 5973 gas chromatograph/mass spectrometer. The column was a DB-5MS capillary column $(30 \mathrm{~m} \times 0.25 \mathrm{~mm} \times 0.2 \mu \mathrm{m})$ and ultra high purity helium was used as the carrier gas at a flow rate of $1 \mathrm{~mL}$ per minute. The injection port temperature was set at $280^{\circ} \mathrm{C}$ and the inlet was operated in the splitless mode (with a 0.75 minute purge delay). The oven temperature was held at $180{ }^{\circ} \mathrm{C}$ for one minute and ramped at $20^{\circ} \mathrm{C}$ per minute to a temperature of $280{ }^{\circ} \mathrm{C}$ and held for 14 minutes. The MSD transfer line was set at $280{ }^{\circ} \mathrm{C}$. The mass spectrometer was used in electron impact (EI) mode at $70 \mathrm{eV}$ and operated in selected ion monitoring (SIM) mode to observe $m / z 283$ for diazepam and 287 for ${ }^{2} \mathrm{H}_{5}$ [phenyl]-diazepam.

\section{Data Analysis}

Standard curves were constructed on each day of analysis using $40 \mu \mathrm{L}$ of ${ }^{2} \mathrm{H}_{5}$-diazepam $(1 \mu \mathrm{g} / \mathrm{mL}$ in methanol) and the amounts of diazepam listed previously. For the plasma samples, chromatographic peaks were integrated by the software and the ratio of $40 \mathrm{ng}$ of ${ }^{2} \mathrm{H}_{5}$-diazepam divided by its area and the area observed for the unknown amount of diazepam were used to calculate the $\mathrm{ng} / \mathrm{mL}$ of diazepam in plasma. 


\section{Preliminary Studies}

In the early stages of the study, the method of blood sampling involved taking samples from the uterine vein, uterine capillary, and peripheral blood at one and five minutes post administration. The procedure was not performed consistently for patients D1-D5. The method then changed to include sampling of peripheral blood at $0,5,10,15$, and 30 minutes during administration and sampling of the uterine vein and capillary blood at 3045 minutes during drug administration. This methodology was used for patients D6 through D19. 


\section{Chapter Four}

\section{Results}

Standard curves were constructed for each analysis and consisted of adding $40 \mu \mathrm{L}$ of ${ }^{2} \mathrm{H}_{5}$ -diazepam $(1 \mu \mathrm{g} / \mathrm{mL}$ in methanol) to concentrations of $1,10,40,100,250$, and 500 $\mathrm{ng} / \mathrm{mL}$ of diazepam in methanol (figure 4.0).

\section{Diazepam Standard Curve}

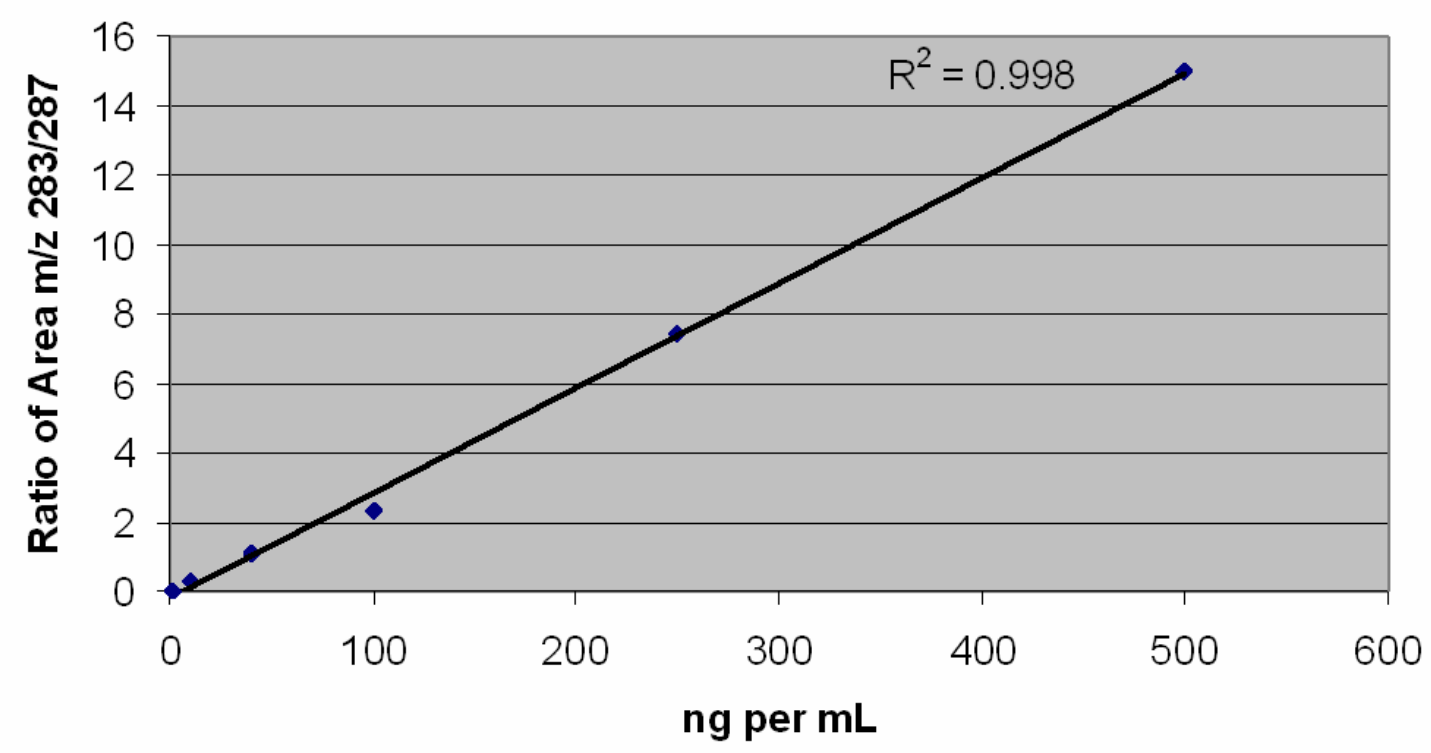

Figure 4.0 Typical standard curve for $1,10,40,100,250$, and $500 \mathrm{ng} / \mathrm{mL}$ of diazepam. 
The quantification performed using the GC/MS was done in a routine manner using the same procedure for every sample. The method used for quantifying diazepam was validated, the limit of detection was $0.5 \mathrm{ng} / \mathrm{mL}$, the assay was sensitive to $1.0 \mathrm{ng} / \mathrm{mL}$ and linear up to $500 \mathrm{ng} / \mathrm{mL}$, and the correlation coefficient was 0.997 . The ${ }^{2} \mathrm{H}_{5}$-diazepam internal standard consistently eluted just before diazepam and always gave similar peak areas and ion counts at $40 \mathrm{ng} / \mathrm{mL}$ (figures 4.1, 4.2). The ion monitored for ${ }^{2} \mathrm{H}_{5}-$ diazepam was $\mathrm{m} / \mathrm{z} 287$ and this resulted from the loss of one deuterium atom (similar to how diazepam lost one hydrogen atom to give $m / z 283$ ).

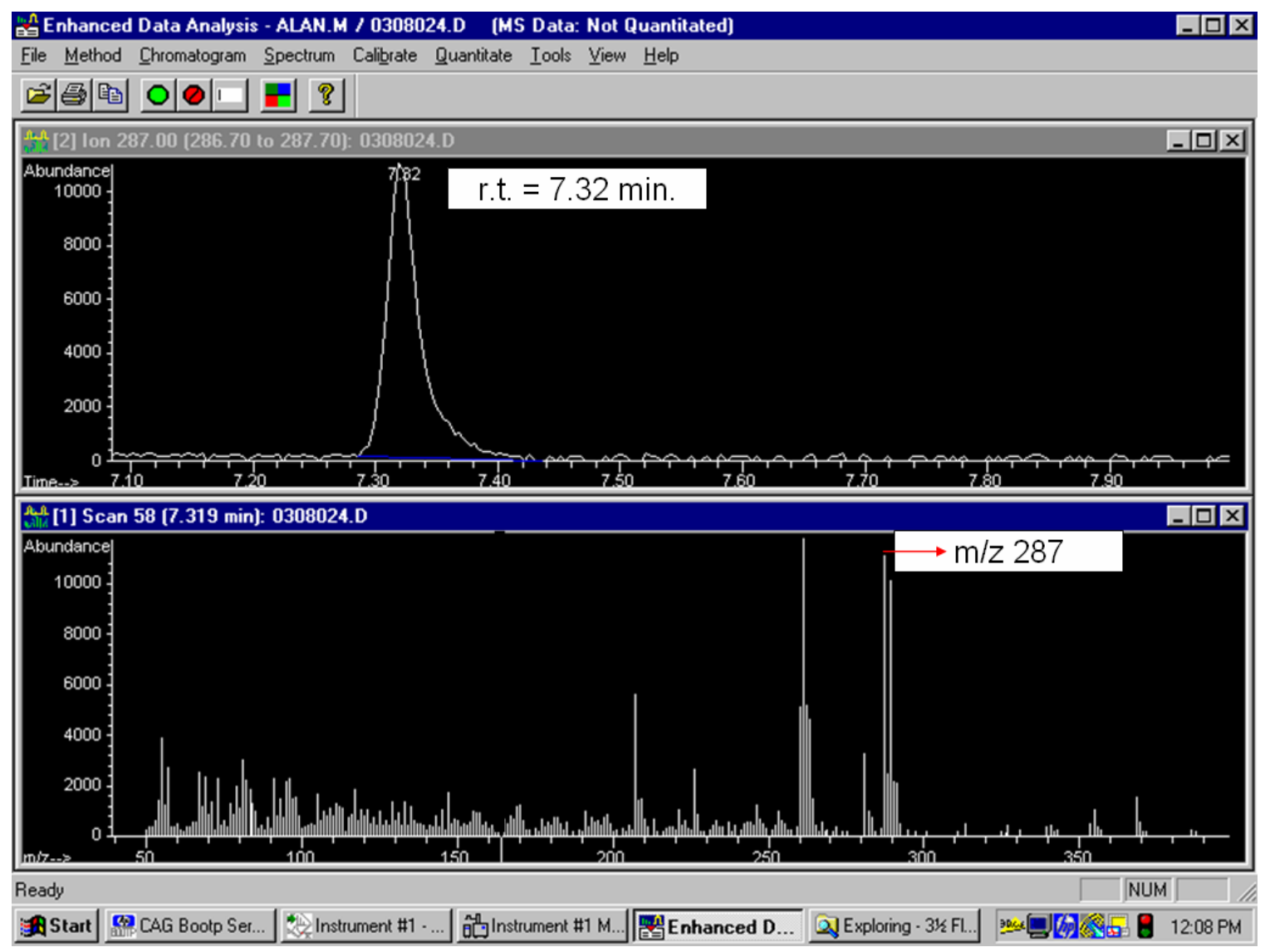

Figure 4.1 Chromatogram and mass spectrum of ${ }^{2} \mathrm{H}_{5}$-diazepam. 


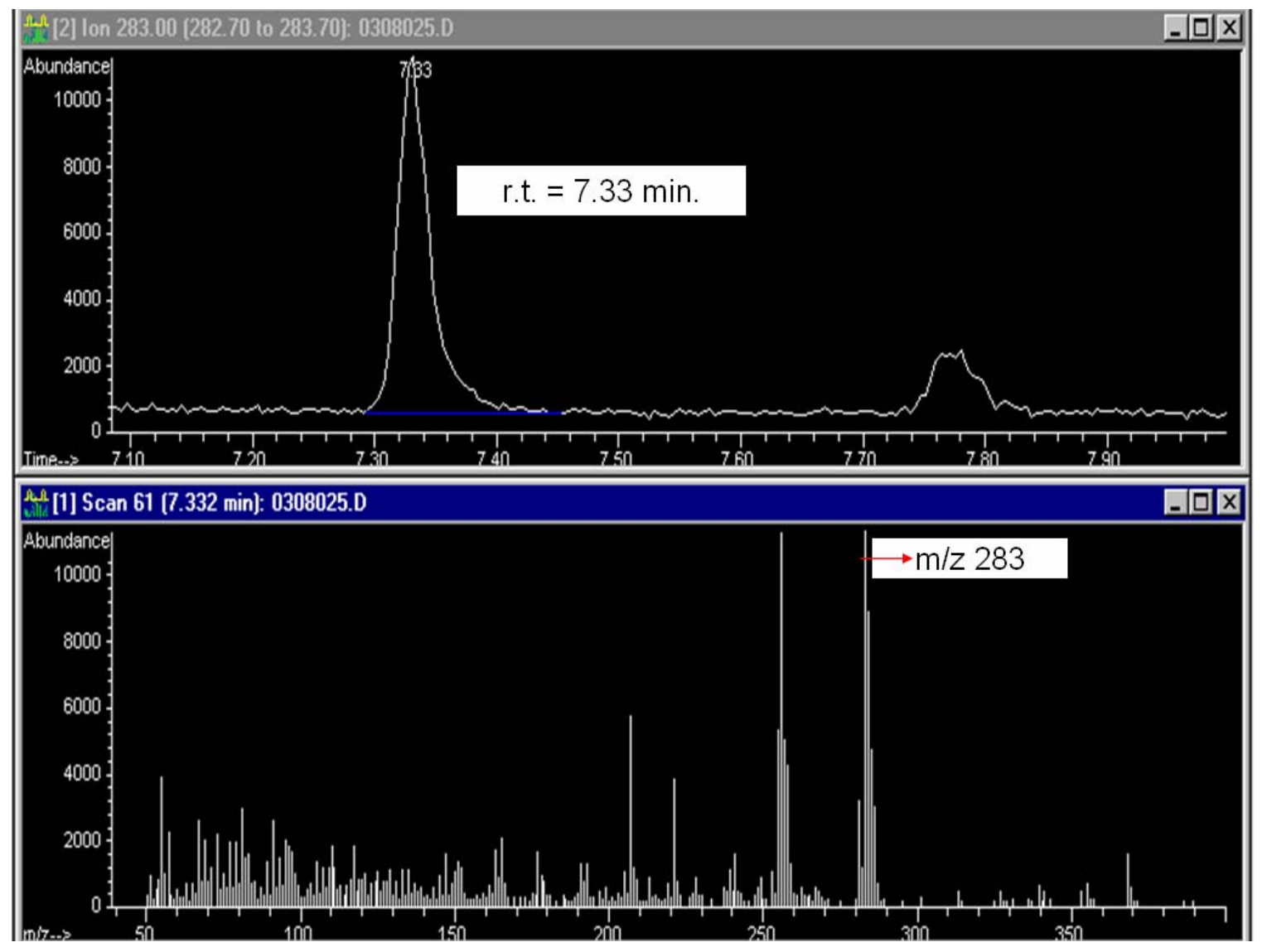

Figure 4.2 Chromatogram and mass spectrum of diazepam. 
The manufacturer of the ${ }^{2} \mathrm{H}_{5}$-diazepam claimed that the isotopic purity was $98 \%$. After obtaining an electrospray spectrum, it was concluded that the claim could be substantiated (figure 4.3).

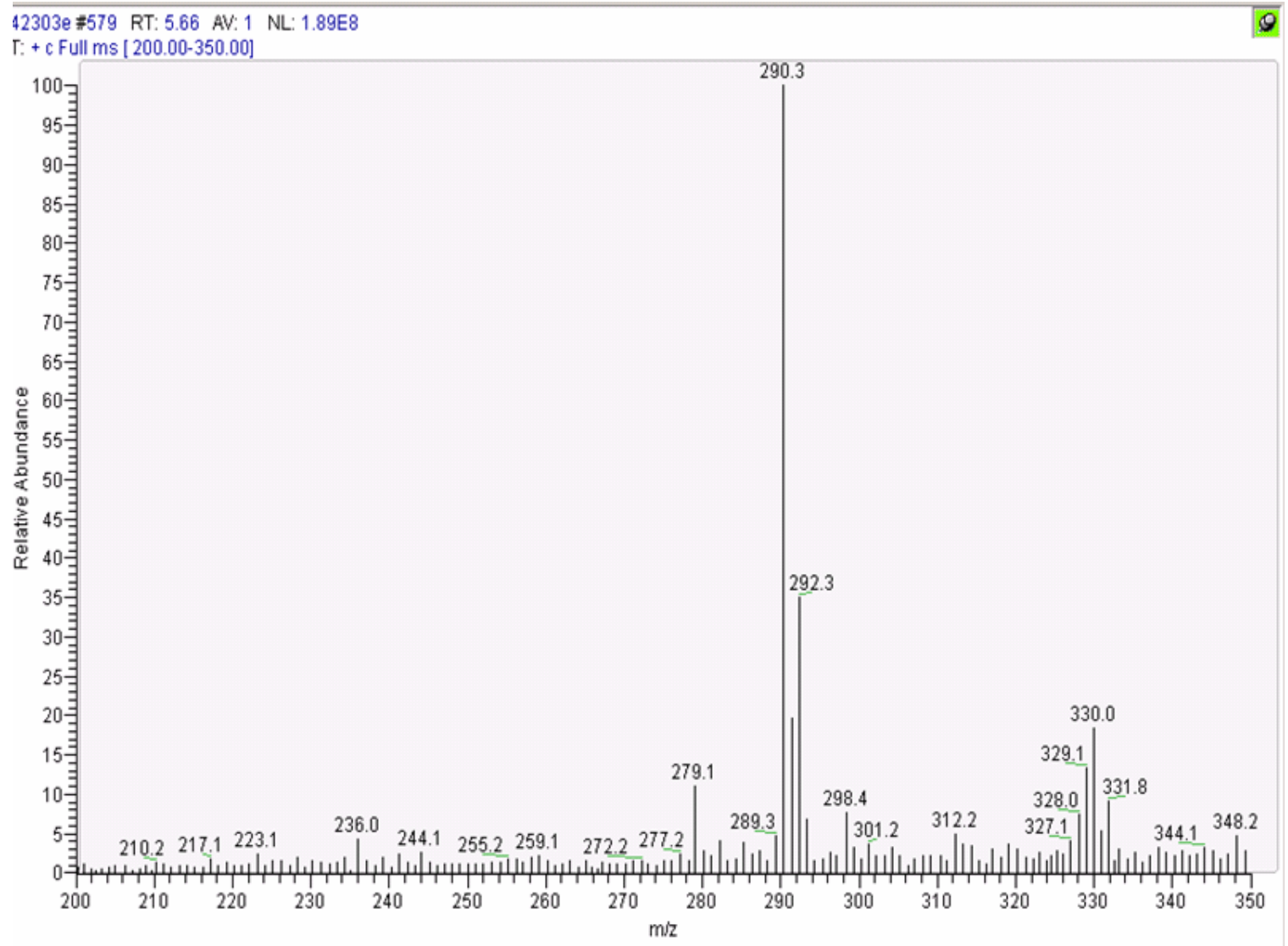

Figure 4.3 An ESI spectrum of ${ }^{2} \mathrm{H}_{5}$-diazepam showing the isotopic purity. 
For some of the patients, circumstances encountered during the surgical procedure prevented the collection of data at the predetermined time intervals. In a couple of cases, the method of sampling did not work well and no diazepam was found in the plasma samples. The graphs that follow are for patients D6 through D19. D14 data were omitted because no diazepam was found in the plasma sample.

The peripheral blood samples from patient D6 shows the concentration of diazepam increasing over time, supporting the conclusion that diazepam was absorbed through the cervix and then entered the general circulation. At 30 minutes during drug administration, the peripheral blood concentration was $27.2 \mathrm{ng} / \mathrm{mL}$, the uterine vein was $238.7 \mathrm{ng} / \mathrm{mL}$, the uterine capillary was $24.1 \mathrm{ng} / \mathrm{mL}$ and thus the concentration found in the uterine vein was almost ten-fold greater than that found in the peripheral blood (figure $4.5,4.6)$. 


\section{D6 Peripheral Plasma}

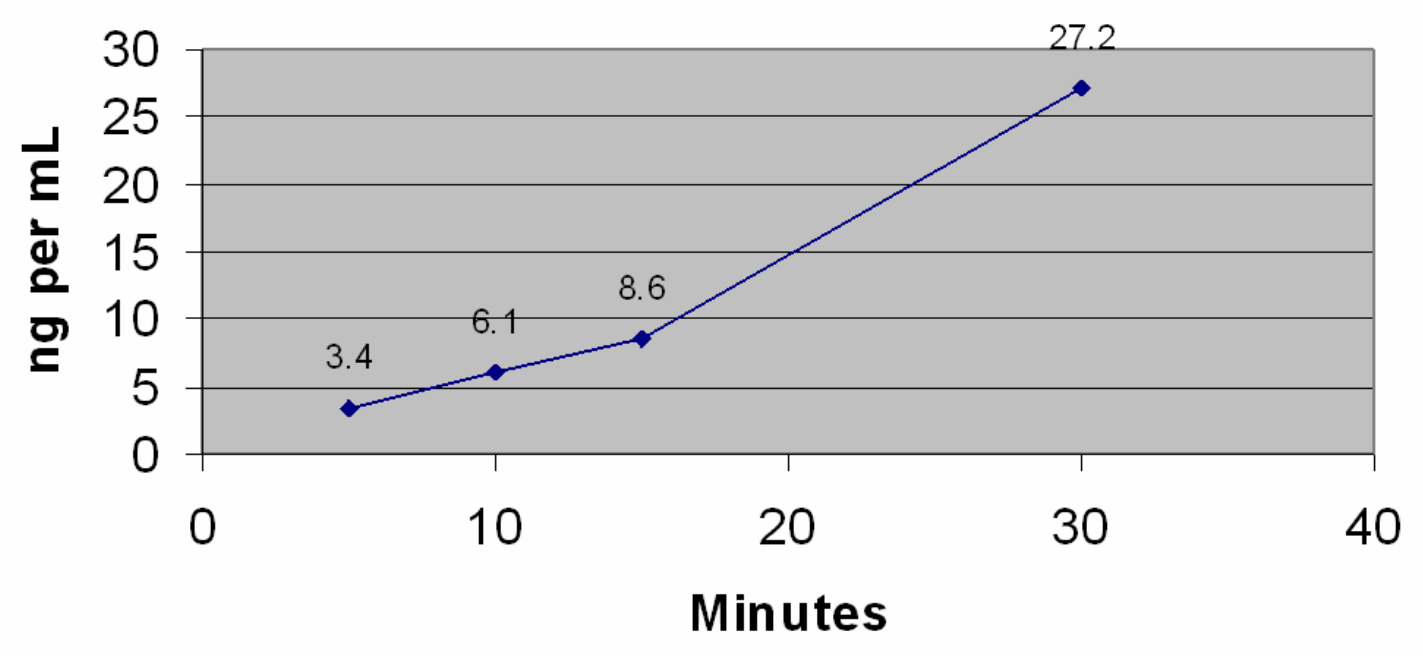

Figure 4.5 Concentration in peripheral plasma in patient D6 after administration of diazepam. 


\section{Patient D6 Plasma}

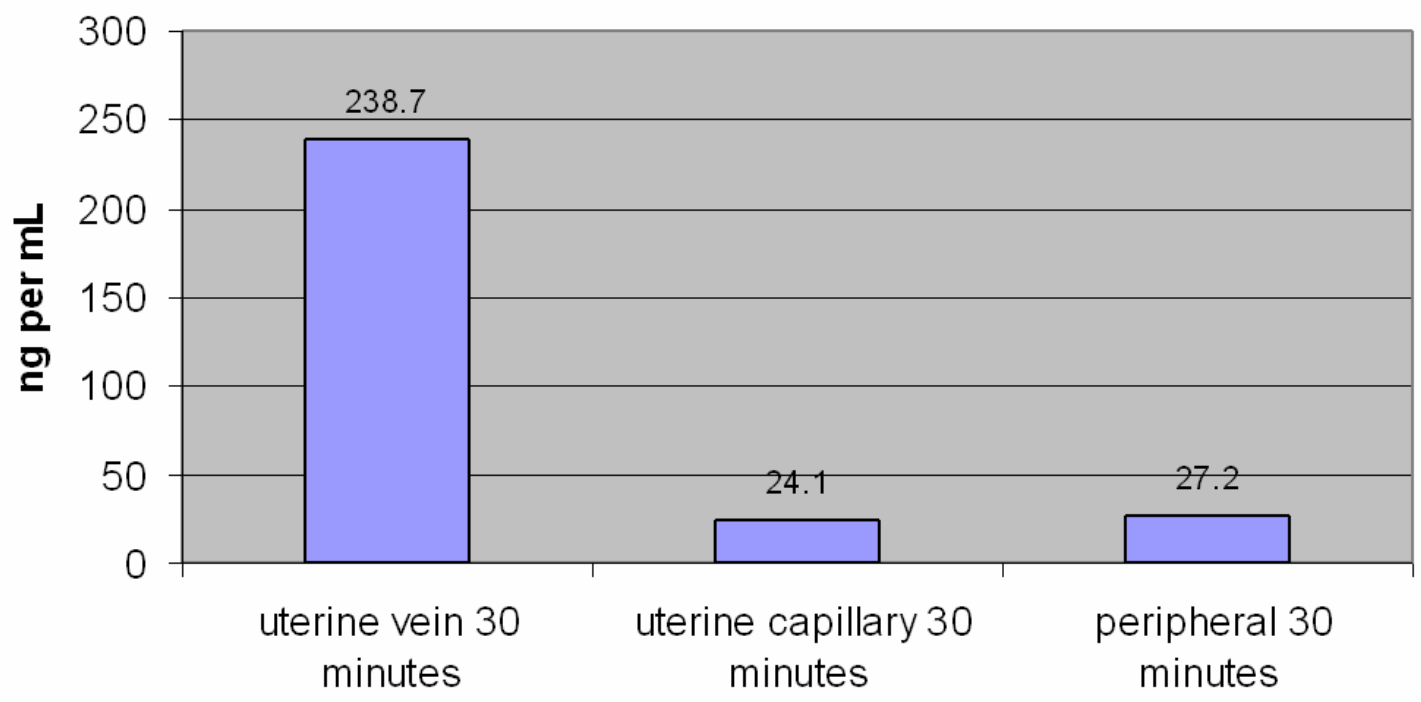

Figure 4.6 Diazepam concentrations in uterine vein, uterine capillary, and peripheral plasma approximately 30 minutes post administration. 
The peripheral blood samples from patient D7 increased over time with the exception of the 30 -minute sample which was slightly less than the 15 -minute sample. The uterine capillary blood sample at 30 minutes was roughly two-fold greater in diazepam concentration than the peripheral blood sample with the highest concentration (40.7 $\mathrm{ng} / \mathrm{mL}$ versus $19.5 \mathrm{ng} / \mathrm{mL})$. 


\section{D7 Peripheral Plasma}

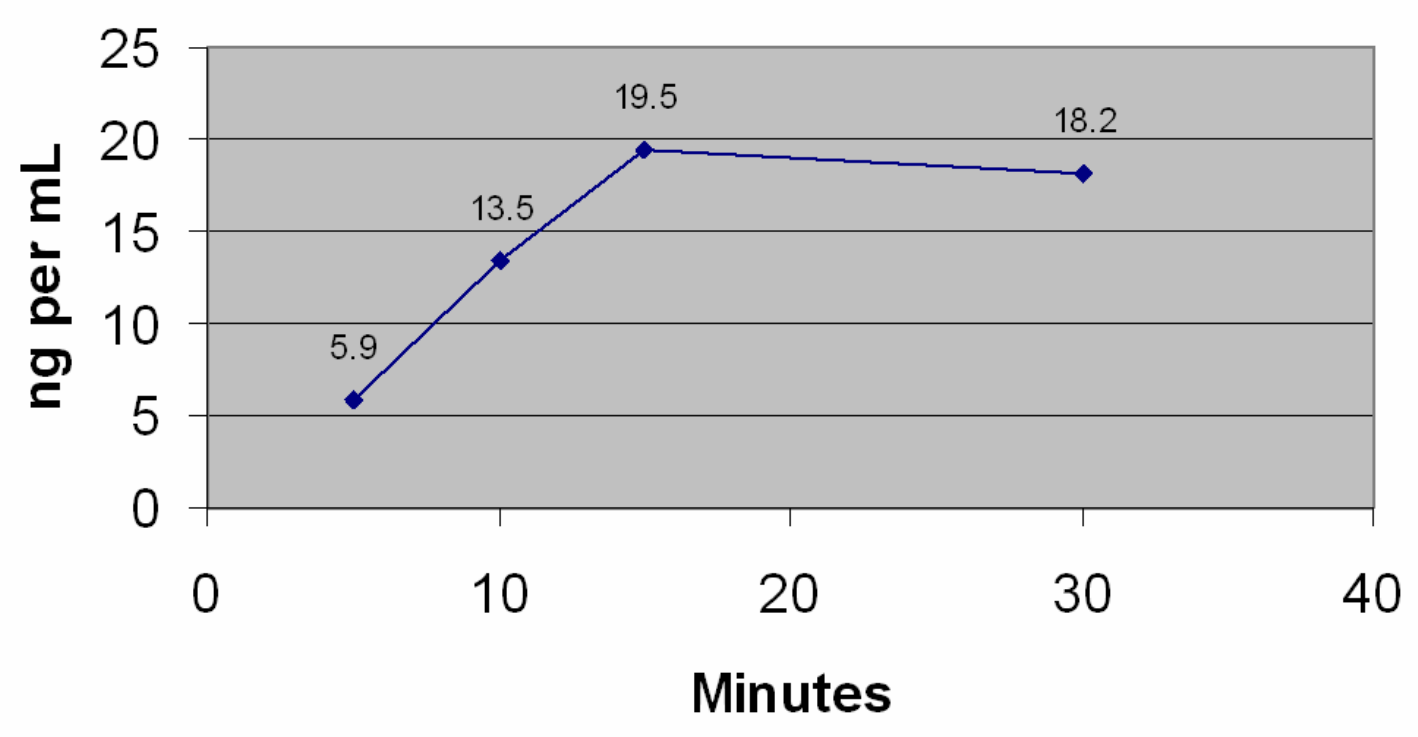

Figure 4.7 Concentration of diazepam in Patient D7 peripheral plasma. 


\section{Patient D7 Plasma}

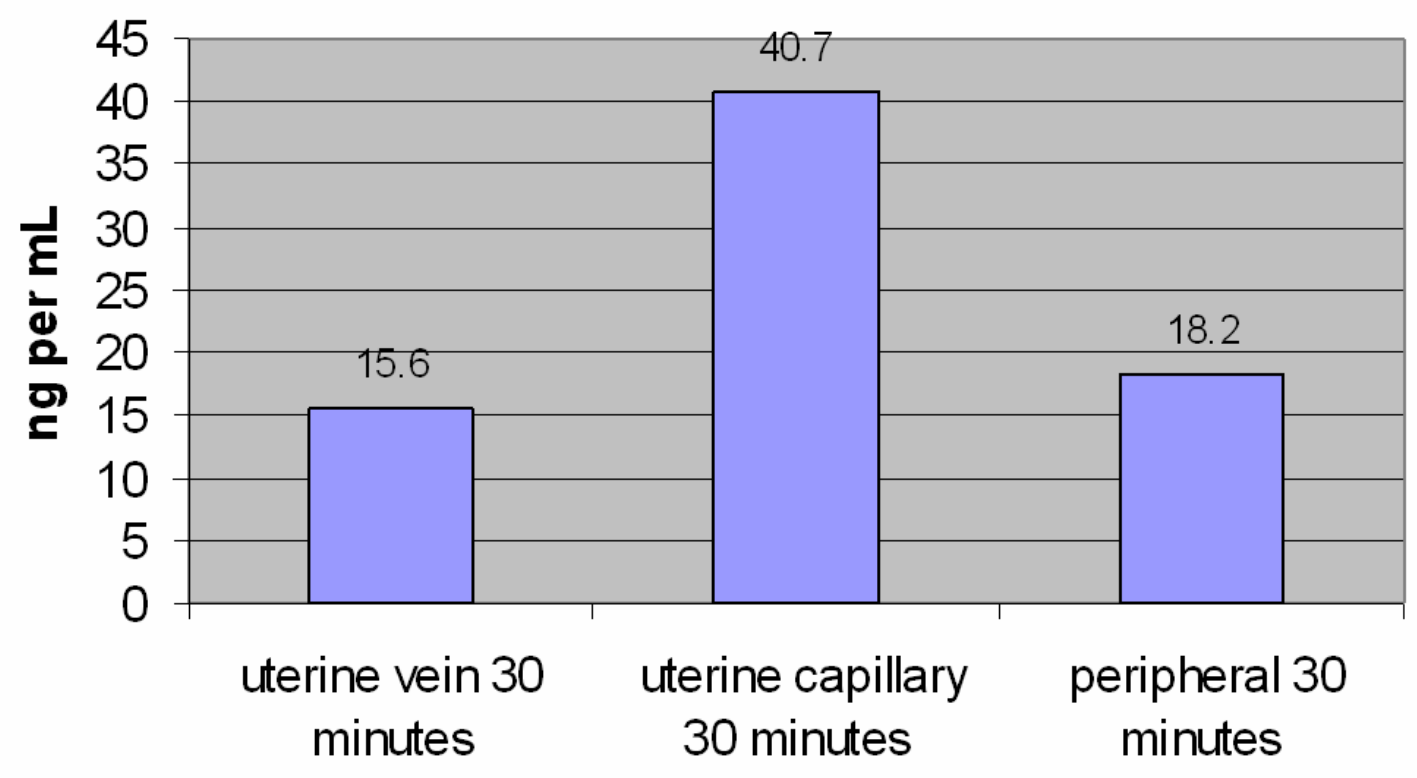

Figure 4.8 Patient D7 plasma concentrations of diazepam approximately 30 minutes post administration. 
The concentration of diazepam increased over time in the peripheral blood of patient D8 with the exception of the 30-minute sample. The highest concentration found in peripheral blood was $15.2 \mathrm{ng} / \mathrm{mL}$ and the concentrations found in the uterine vein and capillary blood were $434.2 \mathrm{ng} / \mathrm{mL}$ and $221.4 \mathrm{ng} / \mathrm{mL}$, respectively. The uterine vein concentration was roughly 29 times greater and the capillary blood was roughly 15 times greater than the highest amount found in peripheral blood $(15.2 \mathrm{ng} / \mathrm{mL})$.

\section{D8 Peripheral Plasma}

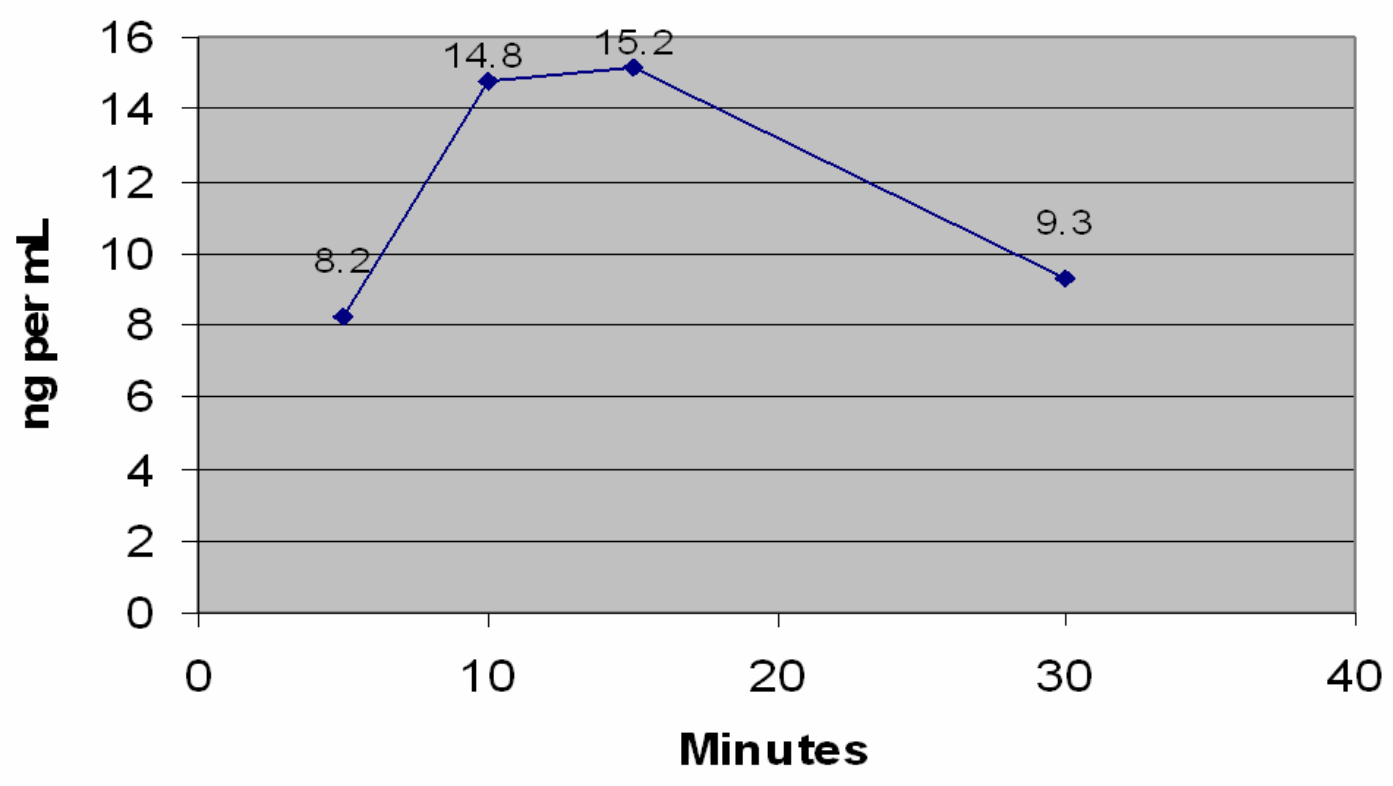

Figure 4.9 Patient D8 diazepam concentration found in peripheral plasma. 


\section{Patient D8 Plasma}

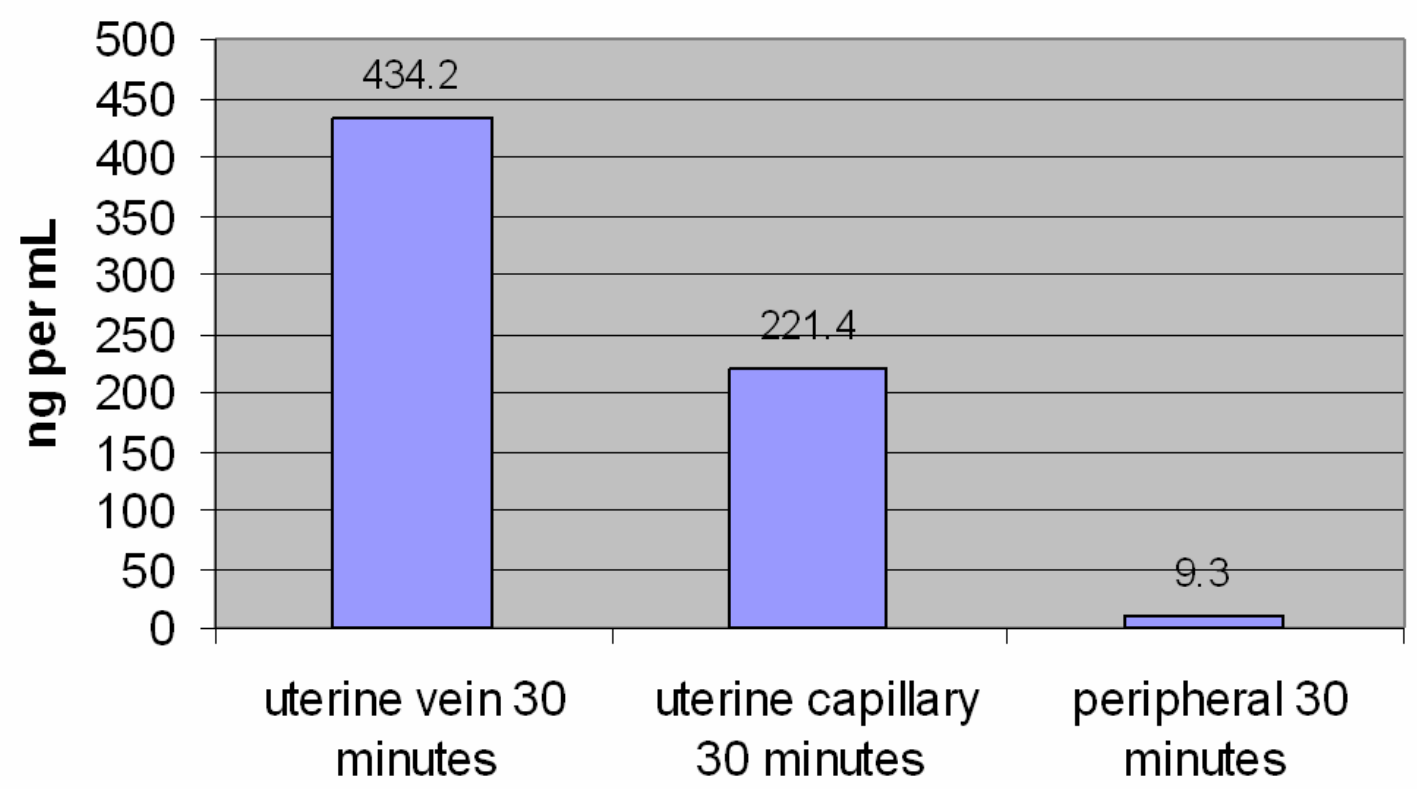

Figure 4.10 Patient D8 diazepam concentrations from the uterine vein, uterine capillary, and peripheral plasma 30 minutes post administration. 
The concentration of diazepam increased over time in the peripheral blood of patient D9 to a maximum of $17.5 \mathrm{ng} / \mathrm{mL}$ at 30 minutes. The concentration found in the uterine capillary blood was $22.4 \mathrm{ng} / \mathrm{mL}$ and in the uterine vein was $17.9 \mathrm{ng} / \mathrm{mL}$.

\section{D9 Peripheral Plasma}

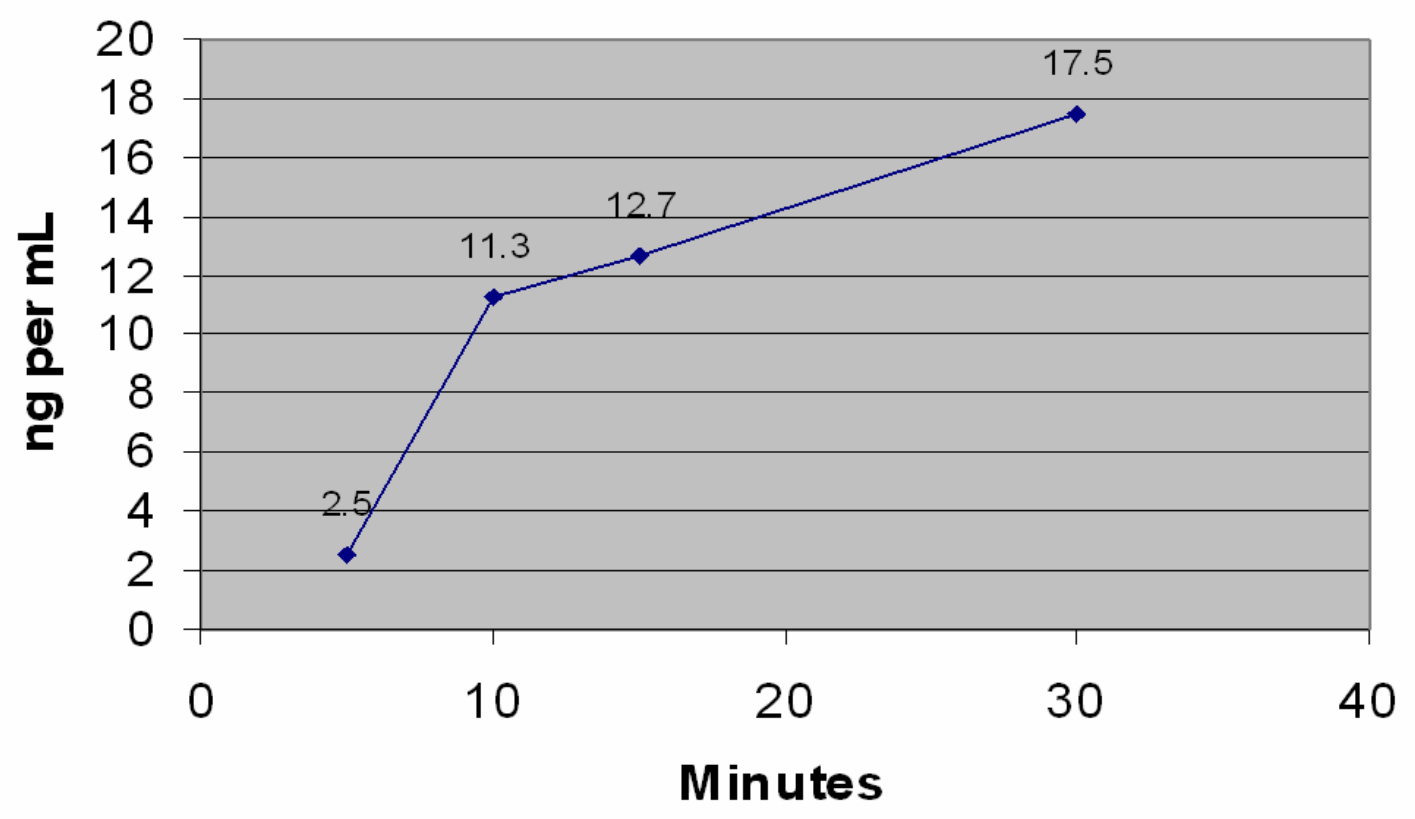

Figure 4.11 Patient D9 diazepam concentration from peripheral plasma. 


\section{Patient D9 Plasma}

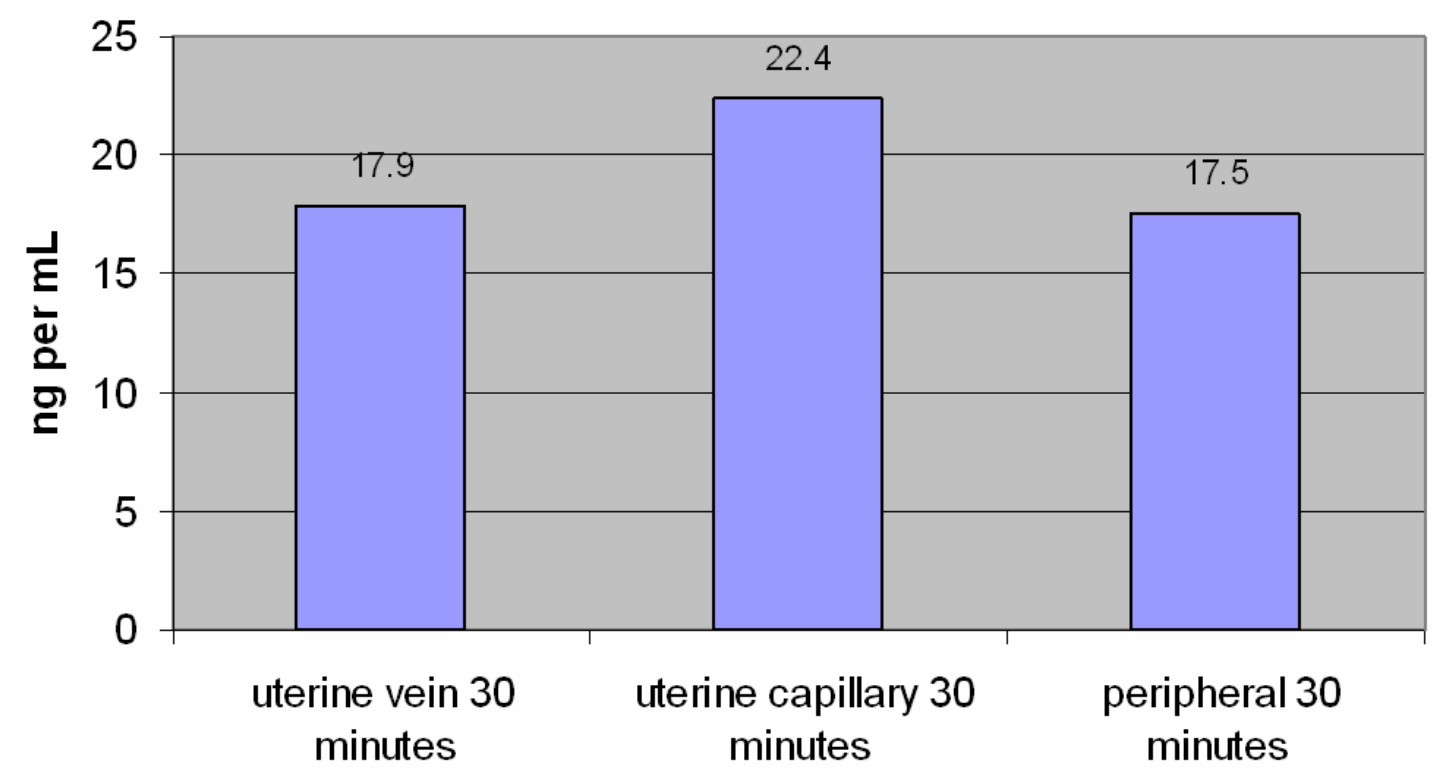

Figure 4.12 Patient D9 diazepam concentration from uterine vein, uterine capillary, and peripheral plasma 30 minutes post administration. 
The concentration of diazepam increased over time in the peripheral blood of patient D10 to a maximum of $5.1 \mathrm{ng} / \mathrm{mL}$ at 30 minutes. The uterine capillary blood at 30 minutes had a concentration of $28.8 \mathrm{ng} / \mathrm{mL}$ and this is roughly 6 times greater than the highest found in peripheral blood. The uterine vein had a concentration of $6.2 \mathrm{ng} / \mathrm{mL}$, which is slightly greater than that found in the peripheral blood at 30 minutes.

\section{D10 Peripheral Plasma}

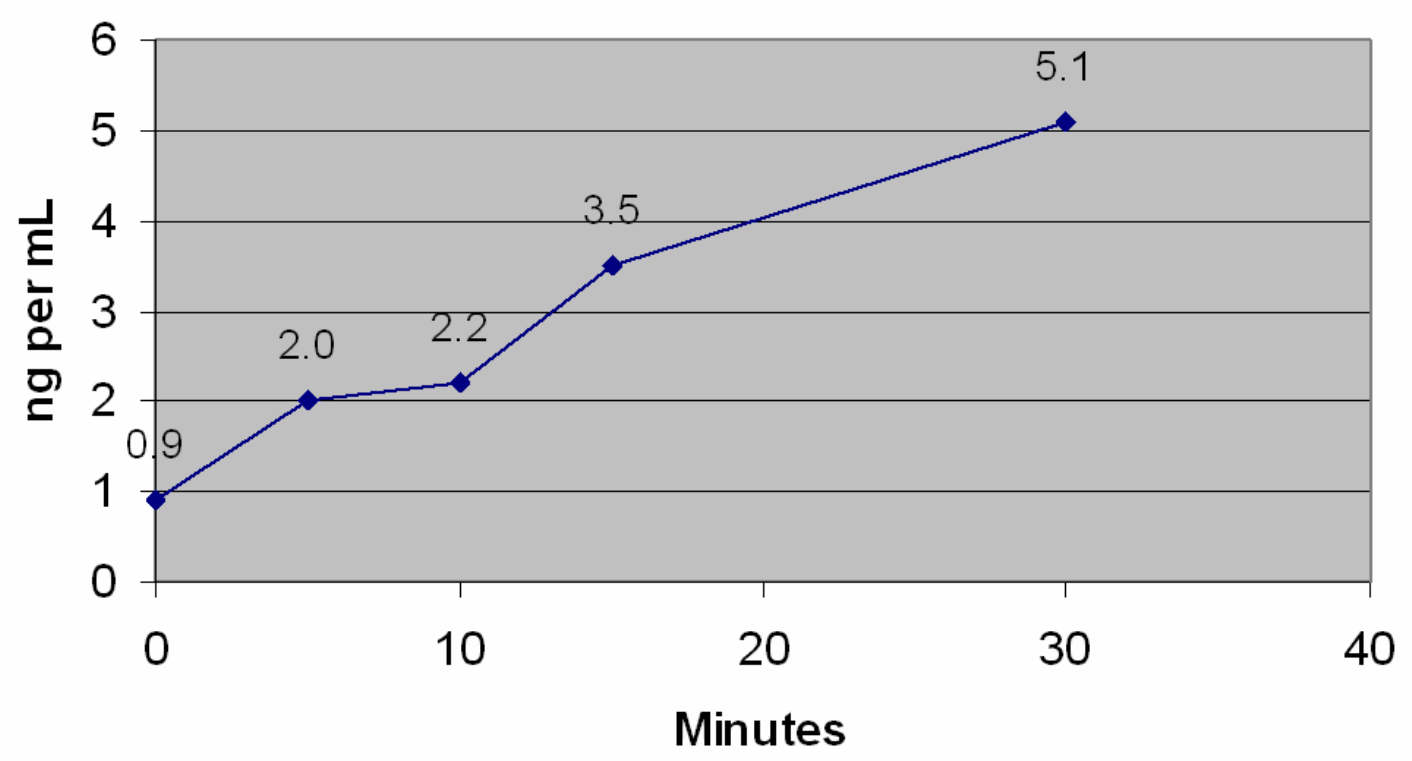

Figure 4.13 Patient D10 diazepam concentration in peripheral plasma. 


\section{Patient D10 Plasma}

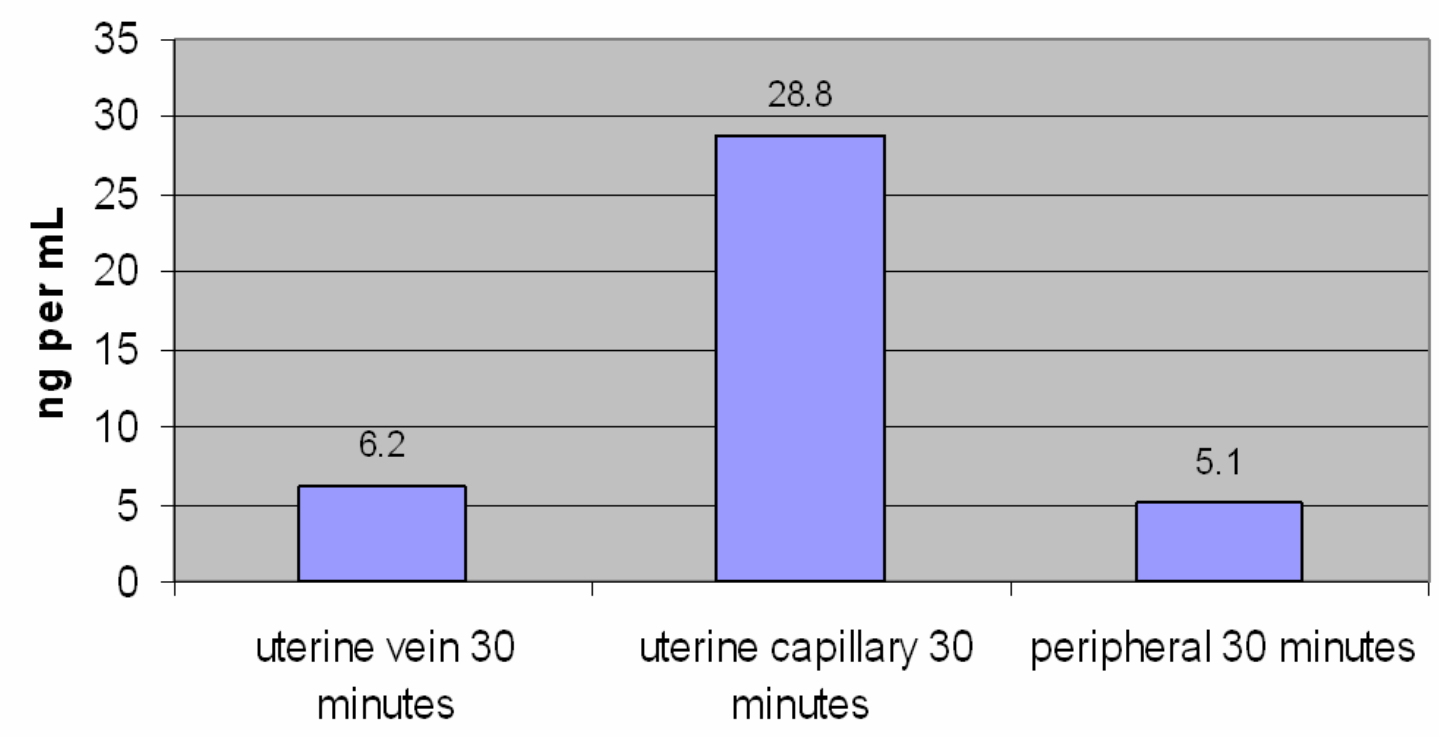

Figure 4.14 Patient D10 diazepam concentration from uterine vein, uterine capillary, and peripheral plasma 30 minutes post administration. 
The concentration of diazepam steadily increased over time in the peripheral blood of patient D1 1 to a maximum of $4.4 \mathrm{ng} / \mathrm{mL}$. The uterine vein had a concentration of 507.1 $\mathrm{ng} / \mathrm{mL}$ at 30 minutes and the uterine capillary blood had $214.1 \mathrm{ng} / \mathrm{mL}$ at 30 minutes and these values are roughly 115 and 49 times greater than the highest found in peripheral blood, respectively. 


\section{D11 Peripheral Plasma}

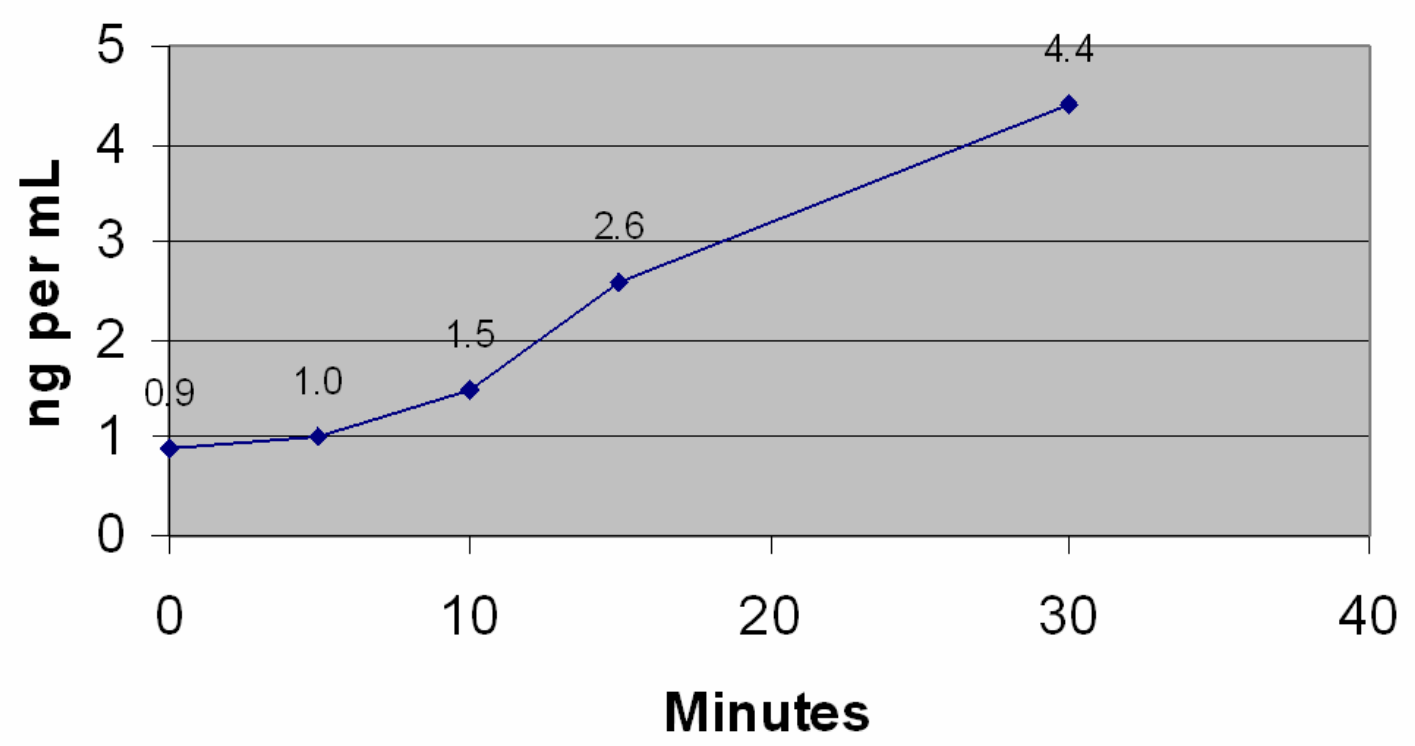

Figure 4.15 Patient D11 diazepam concentration in peripheral plasma. 


\section{Patient D11 Plasma}

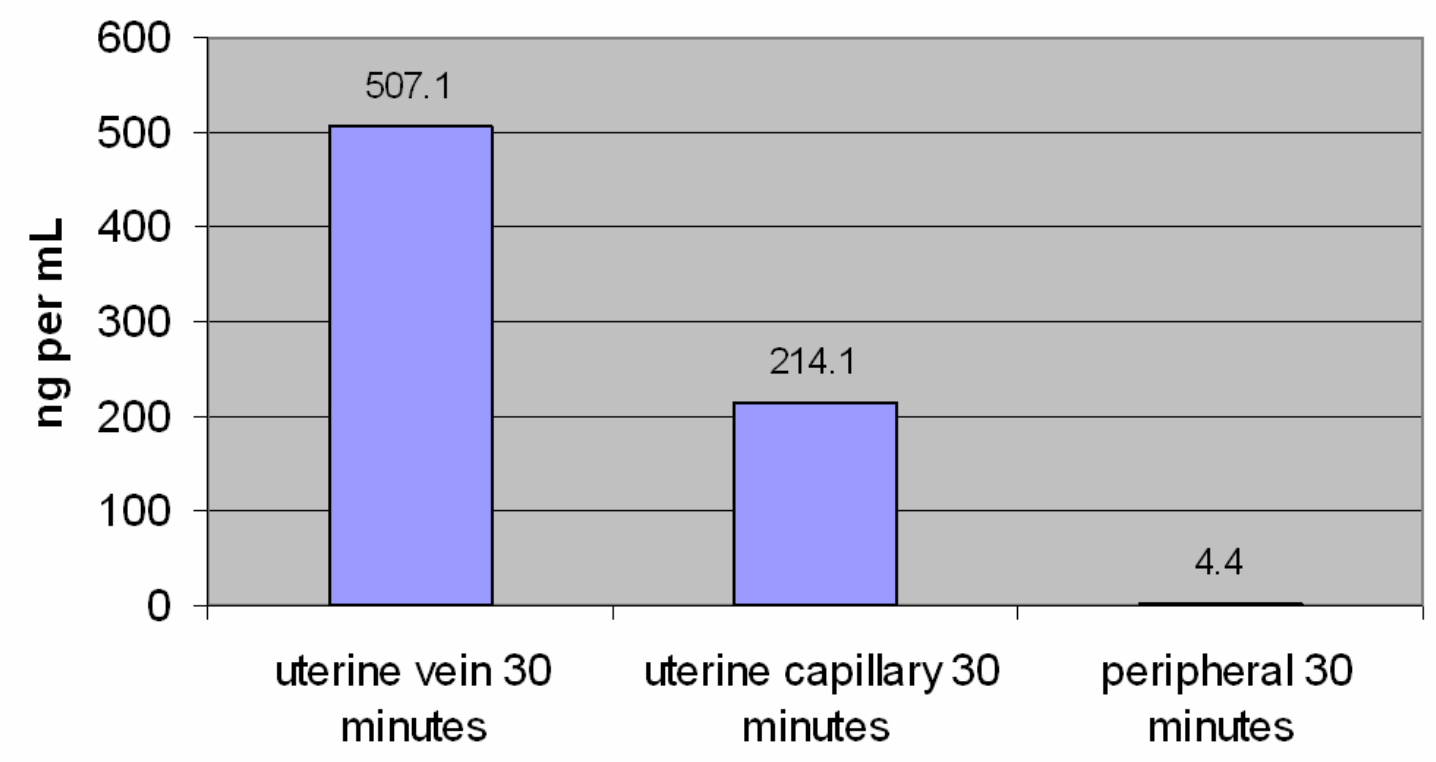

Figure 4.16 Patient D11 diazepam concentrations from uterine vein, uterine capillary, and peripheral plasma 30 minutes post administration. 
The values for peripheral blood increased over time for patient D12 with the exception of the sample taken at 15 minutes. The highest concentration found in peripheral blood was $8.5 \mathrm{ng} / \mathrm{mL}$ at 30 minutes. The uterine vein had $13.3 \mathrm{ng} / \mathrm{mL}$ and the uterine capillary blood had $24.4 \mathrm{ng} / \mathrm{mL}$ and these values are roughly 2 and 3 times greater, respectively.

\section{D12 Peripheral Plasma}

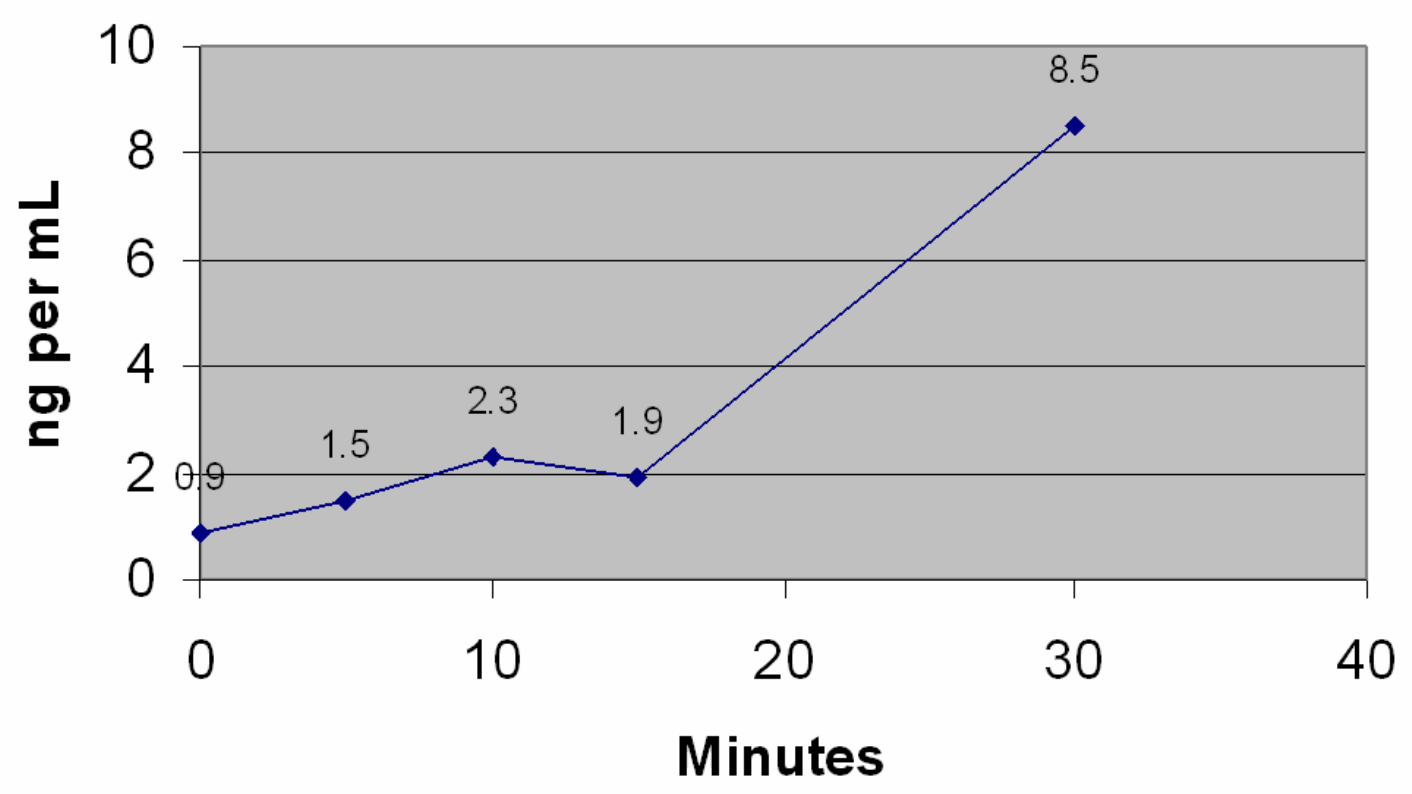

Figure 4.17 Patient D12 diazepam concentration in peripheral plasma. 


\section{Patient D12 Plasma}

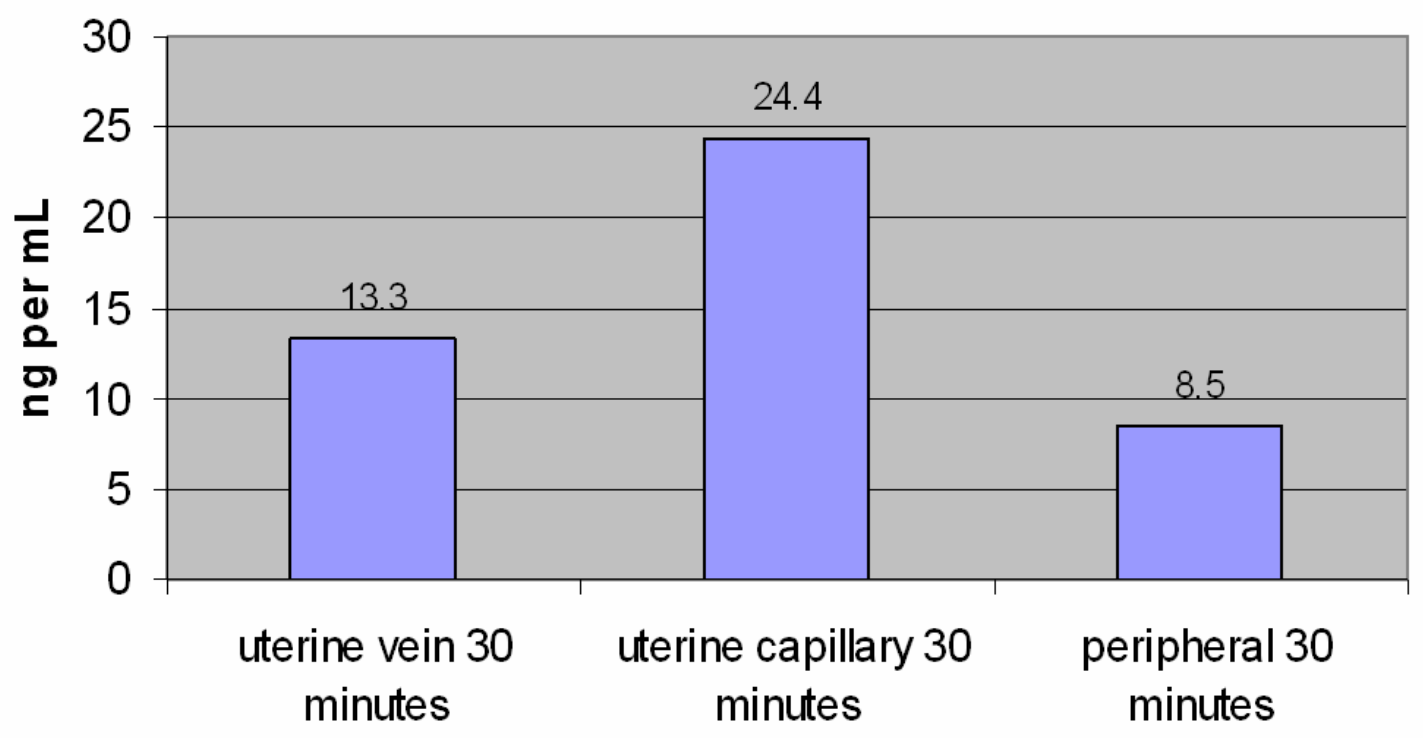

Figure 4.18 Patient D12 diazepam concentration from uterine vein, uterine capillary, and peripheral plasma 30 minutes post administration. 
The diazepam levels at 0 and 5 minutes were below the detection limit for patient D13.

The concentration increased over the last three sampling times to a maximum of 5.1 $\mathrm{ng} / \mathrm{mL}$. The uterine capillary blood had a concentration of $6.0 \mathrm{ng} / \mathrm{mL}$ at 30 minutes, which is slightly greater than the amount found in peripheral blood. The uterine vein had $4.7 \mathrm{ng} / \mathrm{mL}$, slightly less than the amount found in peripheral blood.

\section{D13 Peripheral Plasma}

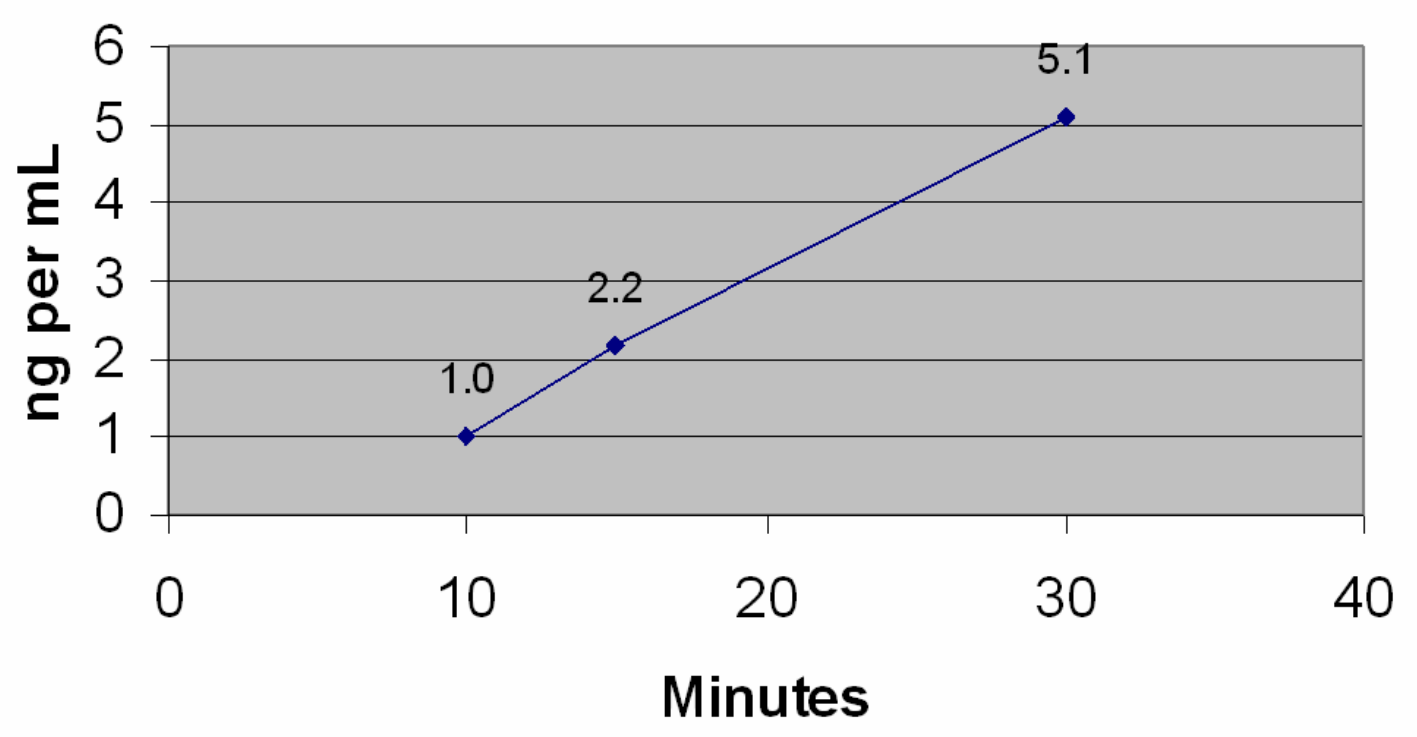

Figure 4.19 Patient D13 diazepam concentration in peripheral plasma. 


\section{Patient D13 Plasma}

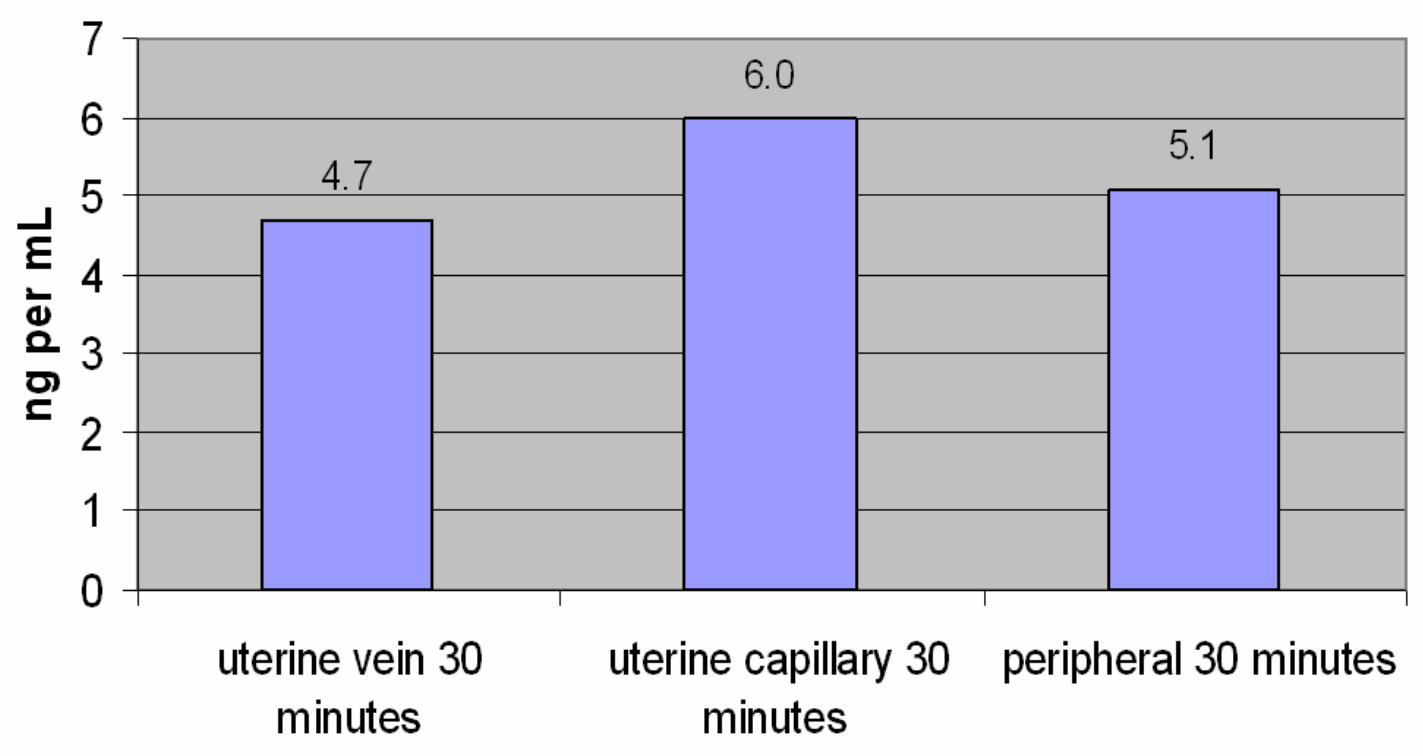

Figure 4.20 Patient D13 diazepam concentration from uterine vein, uterine capillary, and peripheral plasma 30 minutes post administration. 
Diazepam was detected only at the 30-minute sampling time for peripheral blood in patient D15 and the value was $6.1 \mathrm{ng} / \mathrm{mL}$. The uterine vein had $14.5 \mathrm{ng} / \mathrm{mL}$ and the uterine capillary blood had $58.5 \mathrm{ng} / \mathrm{mL}$ and these values are roughly 2 and 10 times greater than the peripheral blood value, respectively.

\section{Patient D15 Plasma}

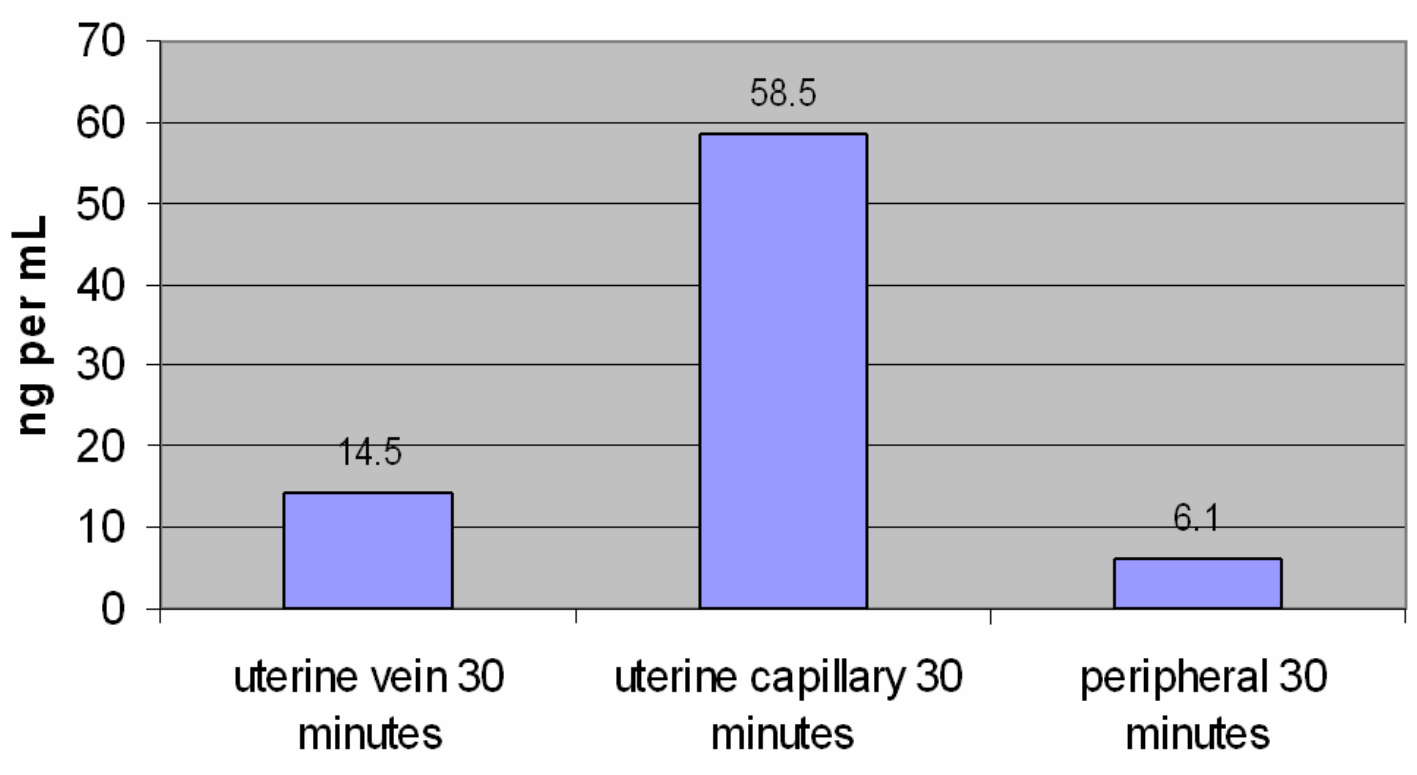

Figure 4.21 Patient D15 diazepam concentration from uterine vein, uterine capillary, and peripheral plasma 30 minutes post administration. 
Diazepam was detected only at the 15 -minute sampling time in patient D16 with a value of $2.4 \mathrm{ng} / \mathrm{mL}$. The uterine vein had $158.6 \mathrm{ng} / \mathrm{mL}$ and the uterine capillary blood had $14.5 \mathrm{ng} / \mathrm{mL}$ and these values are roughly 66 and 6 times greater than the highest found in peripheral blood, respectively.

\section{Patient D16 Plasma}

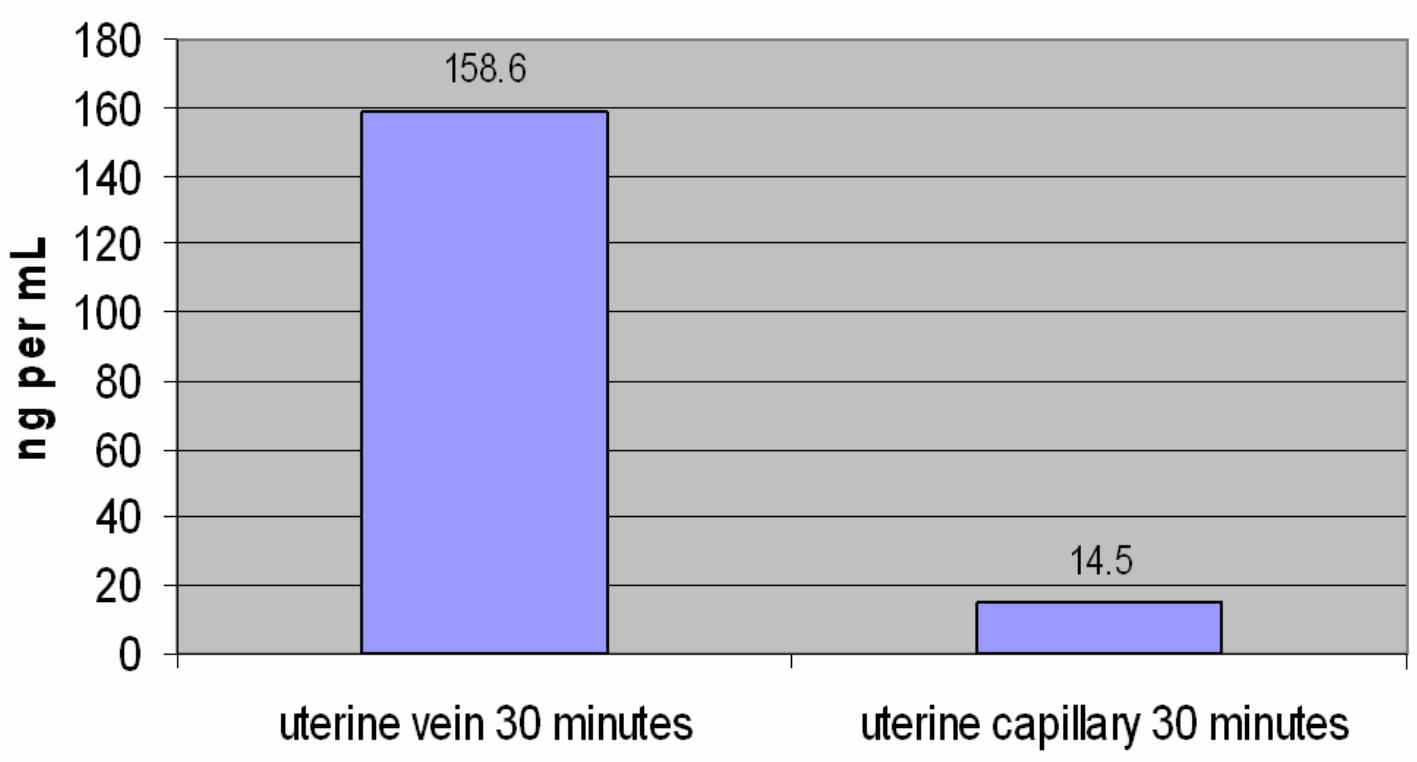

Figure 4.22 Patient D16 diazepam concentration from uterine vein and uterine capillary plasma 30 minutes post administration. 
No diazepam was found in the peripheral blood of patient D17. The uterine vein had 7.9 $\mathrm{ng} / \mathrm{mL}$ and the uterine capillary blood had $4.6 \mathrm{ng} / \mathrm{mL}$.

\section{Patient D17 Plasma}

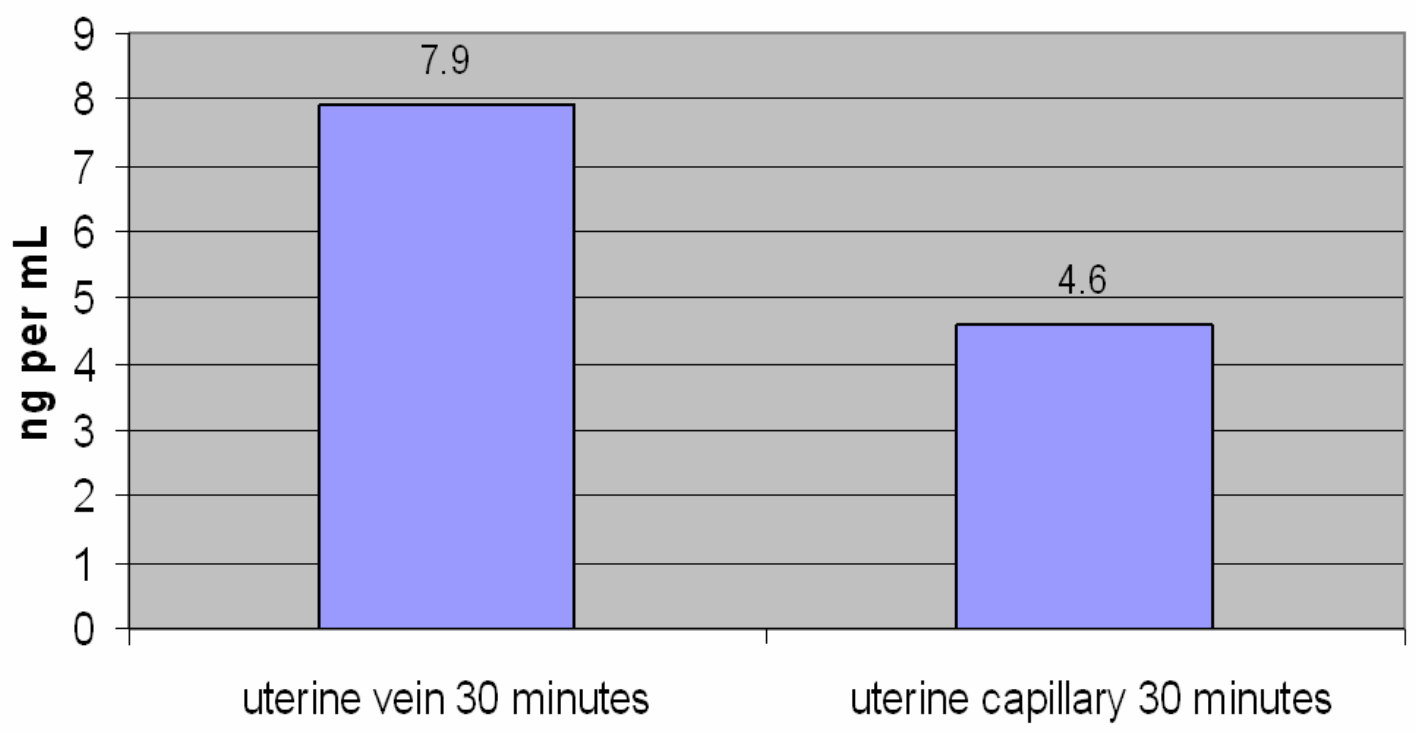

Figure 4.23 Patient D17 diazepam concentration from uterine vein and uterine capillary plasma 30 minutes post administration. 
The concentration of diazepam in peripheral blood increased over time in patient D18 to a maximum of $11.4 \mathrm{ng} / \mathrm{mL}$. The uterine vein had $7.4 \mathrm{ng} / \mathrm{mL}$ and the uterine capillary blood had $44.0 \mathrm{ng} / \mathrm{mL}$. The uterine vein had slightly less and the uterine capillary blood had roughly 4 times the concentration of the highest found in peripheral blood.

\section{D18 Peripheral Plasma}

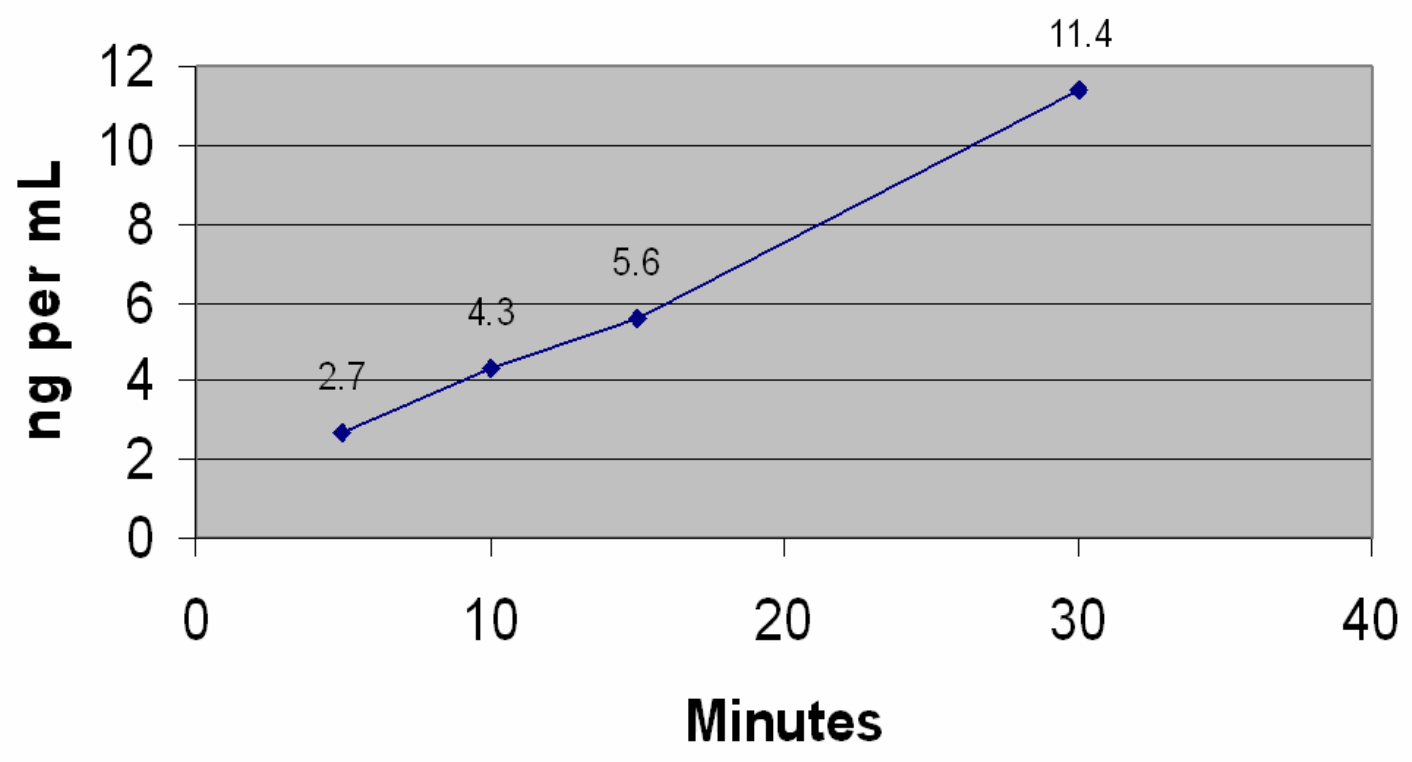

Figure 4.24 Patient D18 diazepam concentration in peripheral blood. 


\section{Patient D18 Plasma}

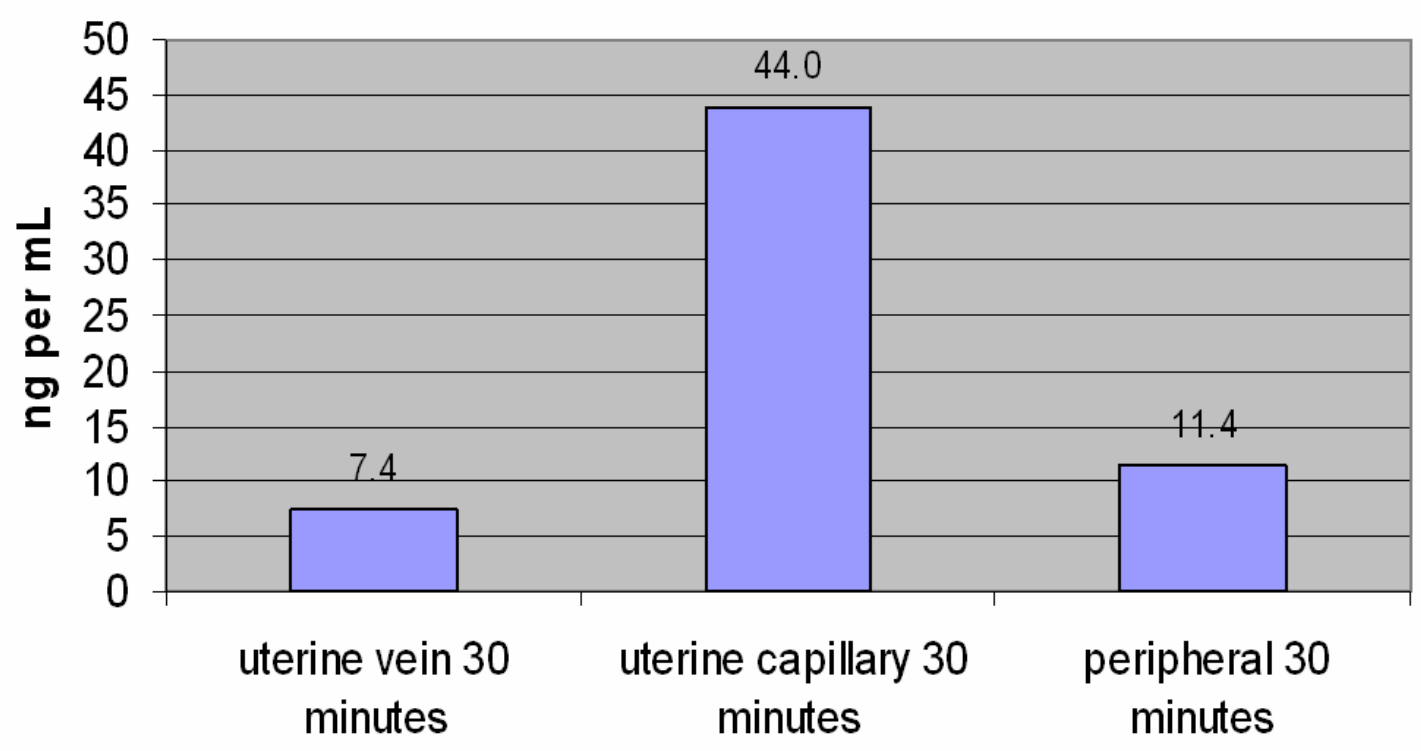

Figure 4.25 Patient D18 diazepam concentration from uterine vein, uterine capillary, and peripheral plasma 30 minutes post administration. 
The highest concentration of diazepam in the peripheral blood of patient D19 was 5.1 $\mathrm{ng} / \mathrm{mL}$ and was found at 30 minutes. The uterine vein had $17.6 \mathrm{ng} / \mathrm{mL}$ and the uterine capillary blood had $63.1 \mathrm{ng} / \mathrm{mL}$ and these values are roughly 3 and 12 times greater than the highest found in peripheral blood, respectively.

\section{D19 Peripheral Plasma}

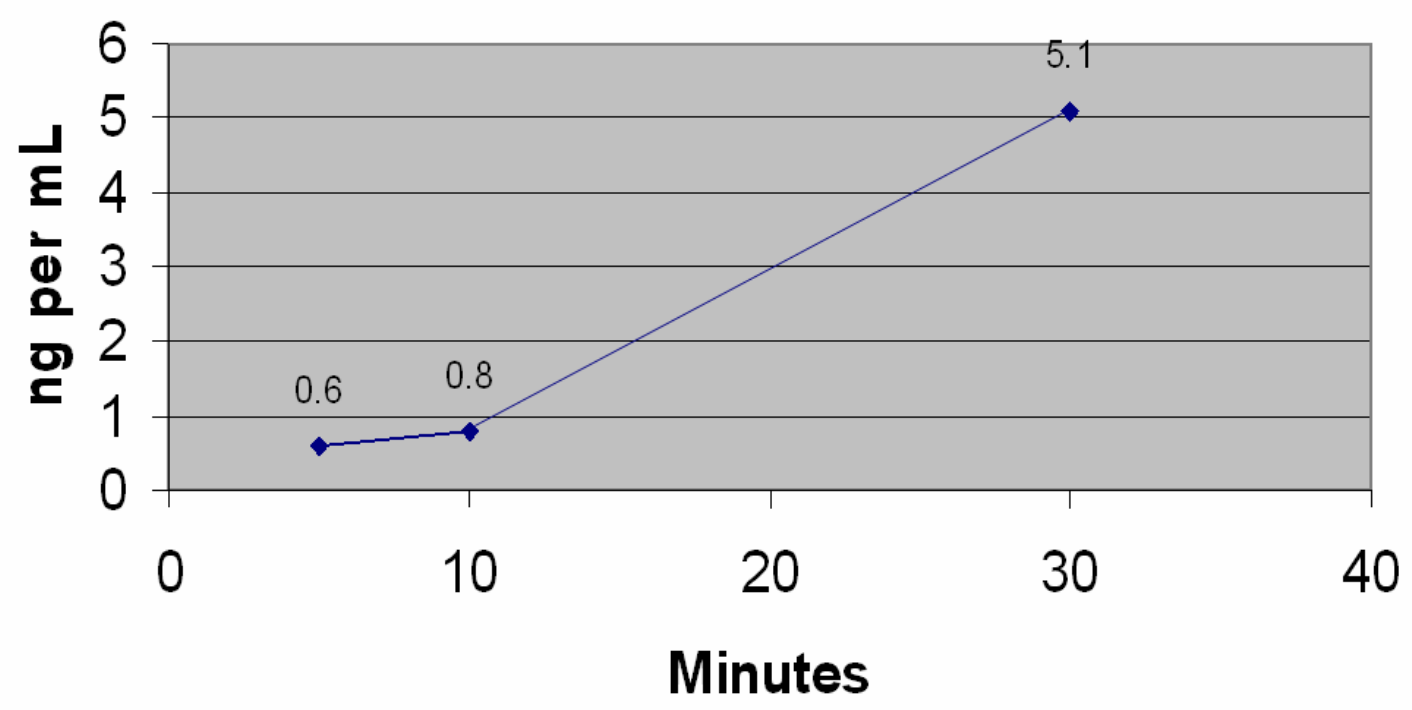

Figure 4.26 Patient D19 diazepam concentration in peripheral plasma. 


\section{Patient D19 Plasma}

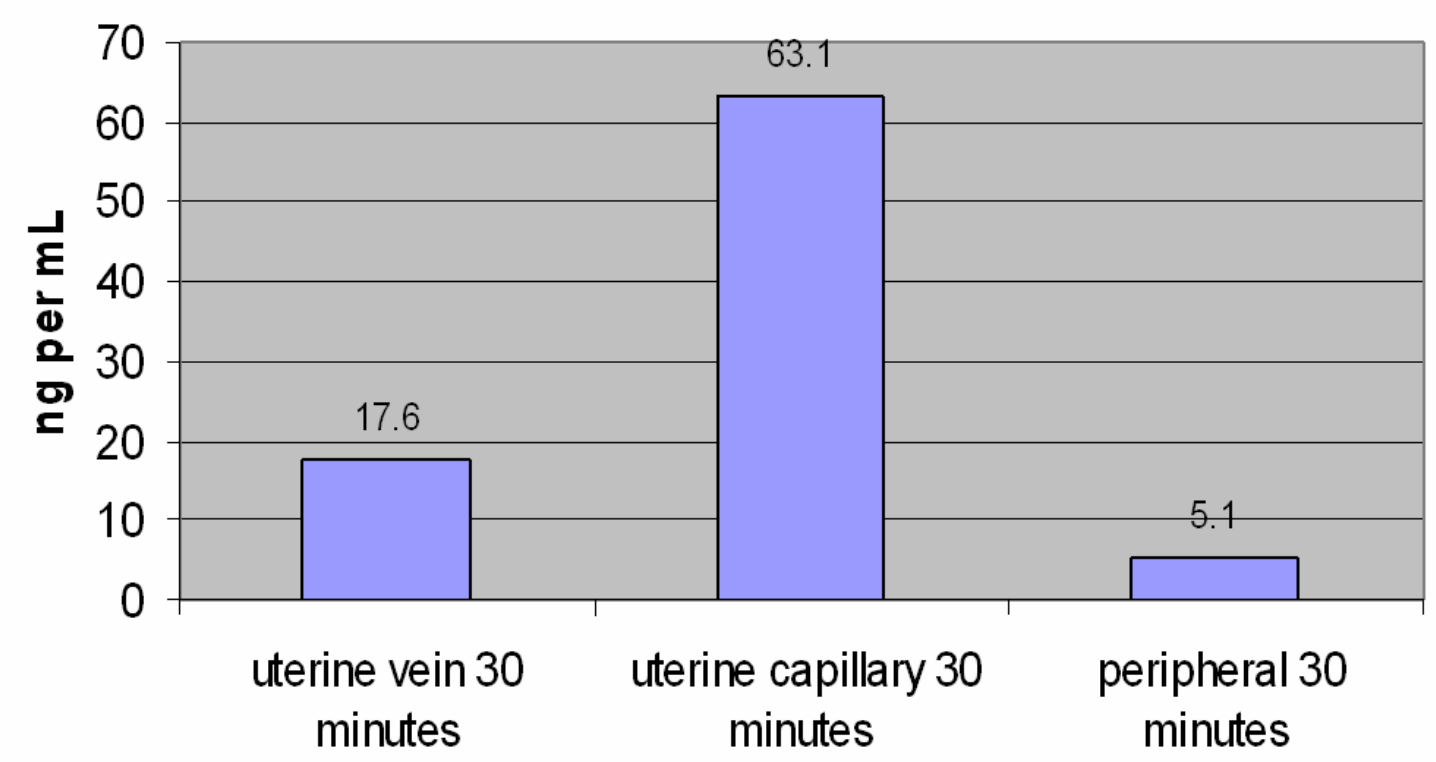

Figure 4.27 Patient D19 diazepam concentration from uterine vein, uterine capillary, and peripheral plasma 30 minutes post administration. 


\begin{tabular}{|c|c|c|c|c|c|c|c|}
\hline & \multicolumn{5}{|c|}{ Peripheral Plasma } & \multirow{2}{*}{$\begin{array}{l}\text { u. vein } \\
30 \mathrm{~min} .\end{array}$} & \multirow{2}{*}{$\begin{array}{l}\text { u. cap. } \\
30 \text { min. }\end{array}$} \\
\hline & $0 \mathrm{~min}$. & $5 \mathrm{~min}$. & $10 \mathrm{~min}$. & $15 \mathrm{~min}$. & $30 \mathrm{~min}$. & & \\
\hline D6 & n.d. & 3.4 & 6.1 & 8.6 & 27.2 & 238.7 & 24.1 \\
\hline D7 & n.d. & 5.9 & 13.5 & 19.5 & 18.2 & 15.6 & 40.7 \\
\hline D8 & n.d. & 8.2 & 14.8 & 15.2 & 9.3 & 434.2 & 221.4 \\
\hline D9 & n.d. & 2.5 & 11.3 & 12.7 & 17.5 & 17.9 & 22.4 \\
\hline D10 & 0.9 & 2.0 & 2.2 & 3.5 & 5.1 & 6.2 & 28.8 \\
\hline D11 & 0.9 & 1.0 & 1.5 & 2.6 & 4.4 & 507.1 & 214.1 \\
\hline D12 & 0.9 & 1.5 & 2.3 & 1.9 & 8.5 & 13.3 & 24.4 \\
\hline D13 & n.d. & n.d. & 1.0 & 2.2 & 5.1 & 4.7 & 6.0 \\
\hline D14 & n.d. & n.d. & n.d. & n.d. & n.d. & n.d. & n.d. \\
\hline D15 & n.d. & n.d. & n.d. & n.d. & 6.1 & 14.5 & n.d. \\
\hline D16 & n.d. & n.d. & n.d. & 2.4 & n.d. & 158.6 & n.d. \\
\hline D17 & n.d. & n.d. & n.d. & n.d. & n.d. & 7.9 & 4.6 \\
\hline D18 & n.d. & 2.7 & 4.3 & 5.6 & 11.4 & 7.4 & 44.0 \\
\hline D19 & n.d. & 0.6 & 0.8 & n.d. & 5.1 & 17.6 & 63.1 \\
\hline average & 0.9 & 3.1 & 5.8 & 7.4 & 10.7 & 111.1 & 63.1 \\
\hline std. dev. & 0 & 2.5 & 5.4 & 6.3 & 7.3 & 175.3 & 78.3 \\
\hline \multicolumn{3}{|c|}{ *n.d. is not detected } & & & & & \\
\hline
\end{tabular}

Figure 4.28 Data table for diazepam patients D6-D19. 


\section{Chapter Five}

\section{Discussion}

In concurrence with data by Woolfson and coworkers [4,5], it appears that it is possible for a drug to be absorbed when applied directly to the cervix. The following patients had a higher concentration of diazepam in either the uterine vein or uterine capillary blood sample, or both when compared to the highest concentration found in peripheral blood: D6, D7, D8, D9, D10, D11, D12, D13, D15, D16, D18, and D19. Three of the patients had very high concentrations of diazepam in the uterine blood with relatively low amounts found in the peripheral blood. Patient D6 had $238.7 \mathrm{ng} / \mathrm{mL}$ in the uterine vein sample, $24.1 \mathrm{ng} / \mathrm{mL}$ in the uterine capillary blood sample, and $27.2 \mathrm{ng} / \mathrm{mL}$ in the peripheral sample with the highest concentration. Patient D8 had $434.2 \mathrm{ng} / \mathrm{mL}$ in the uterine vein sample, $221.4 \mathrm{ng} / \mathrm{mL}$ in the uterine capillary blood sample, and $15.2 \mathrm{ng} / \mathrm{mL}$ in the peripheral sample with the highest concentration. Patient D11 had $507.1 \mathrm{ng} / \mathrm{mL}$ in the uterine vein sample, $214.1 \mathrm{ng} / \mathrm{mL}$ in the uterine capillary blood sample, and 4.4 $\mathrm{ng} / \mathrm{mL}$ in the peripheral sample with the highest concentration. It is unclear why these three patients had substantially higher concentrations in uterine blood when compared to the rest of the subjects. Patient D13 had uterine blood concentrations of 4.7 and 6.0 $\mathrm{ng} / \mathrm{mL}$ and the highest peripheral blood concentration was $5.1 \mathrm{ng} / \mathrm{mL}$. The active metabolite of diazepam (nordiazepam) was not detected in any of the samples tested. A statistical t-test was calculated and the results showed that the concentration of diazepam was higher in uterine blood than in peripheral blood at the 95 percent confidence level. The doctors performing the surgery indicated that circumstances involved with the surgery sometimes interfered with taking blood samples at the predetermined times and it 
would be beneficial to have more trials to streamline the techniques. It is unclear whether or not the placement of the delivery device was precise enough to be in close contact with the cervix for the duration of drug delivery. No patient history was incorporated into the study. Patients may have had previous surgery on the cervix and the presence of scar tissue would affect drug absorption. The weight of the patient could also have an impact on drug absorption because of its lipophilic nature. 


\section{Chapter Six}

\section{Conclusion}

A sensitive, specific quantitative assay for diazepam was developed based on gas chromatography/mass spectrometry. Stable isotope labeled diazepam was used as an internal standard. The current studies support the concept of cervical absorption of drugs. Subsequent uptake by uterine tissue was also observed. The study showed that the cervix could absorb a drug when directly applied to its surface and higher concentrations are found in uterine blood than peripheral blood suggesting tissue selectivity 30 minutes during application. Some of the patients had very high concentrations in the uterine blood samples. This means it may be possible to deliver other drugs in a similar manner and observe high blood concentrations only where it is desired (the uterus). Further studies using anti-cancer drugs and drugs used to treat other cervical and uterine diseases should be considered. 


\section{Reference List}

1. Ansel, Howard C., Pharmaceutical Dosage Forms and Drug Delivery Systems. Malvern, PA: Williams and Wilkins, 1995.

2. Coassolo CD, Aubert C, Coassolo P, and Cano JP. Capillary Gas ChromatographicMass Spectrometric Method for the Identification and Quantification of Some Benzodiazepines and their Unconjugated Metabolites in Plasma, Journal of Chromatography, 487 (1989) 295-311.

3. http://masspec.scripps.edu/information/history

4. Woolfson AD, McCafferty DF, McCarron PA, and Price JH. Liquid Scintillation Spectrometry of 5-Fluorouracil in Cervical Tissue Following in Vitro Surface Application of a Bioadhesive Cervical Patch. Pharmaceutical Research, Vol. 11, No. 9, 1994.

5. Woolfson AD, McCafferty DF, McCarron PA, and Price JH. Autoradiographic Imaging of the Distribution of 5-Fluorouracil Through Cervical Tissue Following in Vitro Surface Application of a Bioadhesive Cervical Patch. Pharmaceutical Research, Vol. 12, No. 5, 1995.

6. Millard BJ. Quantitative Mass Spectrometry. Heyden, 1978.

7. Ansel HC, Allen LV, and Popovich NG. Pharmaceutical Dosage Forms and Drug Delivery Systems, $7^{\text {th }}$ Edition. Lippincott Williams and Wilkins 1999.

8. Kistner RW. Gynecology Principles and Practice, $3^{\text {rd }}$ Edition. Year Book Medical Publishers, 1979.

9. Inoue H, Maeno Y, Iwasa M, Matoba R, and Nagao M. Screening and Determination of Benzodiazepines in Whole Blood using Solid-phase Extraction and Gas Chromatography/Mass Spectrometry. Forensic Science International, 2000, Vol. $113,367-373$.

10. Choi HK and Callery PS. Simultaneous Determination of Underivatized Diazepam and Nordiazepam in Plasma using Gas Chromatography/Mass Spectrometry. Abstract, American Academy of Forensic Sciences National Meeting, Atlanta, GA, Feb. 2002.

11. Kronstrand R, Nystrom I, Josefsson M, and Hodgins S. Segmental Ion Spray LC/MSMS Analysis of Benzodiazepines in Hair of Psychiatric Patients. Journal of Analytical Toxicology, 2002, Vol. 7, No. 26, 479-84. 
12. Turci R, Angeleri F, and Minoia C. A rapid screening method for routine congenerspecific analysis of polychlorinated biphenyls in human serum by high-resolution gas chromatography with mass spectrometric detection. Rapid Communications in Mass Spectrometry, 2002, Vol. 16, No. 20, 1957-1964.

13. Zemaitis M, Poloyac S, and Frye R. Identification of omega hydroxy fatty acids in biological samples as their pentafluoropropyl derivatives by gas chromatography/mass spectrometry with positive and negative ion detection. Rapid Communications in Mass Spectrometry, 2002, Vol. 16, No. 15, 1411-1415.

14. Bluck L, Jones K, and Bates C. ${ }^{2} \mathrm{H}$ - and ${ }^{13} \mathrm{C}$-Labelled tracers compared for kinetic studies of ascorbic acid metabolism in man: a factor analytical approach. Rapid Communications in Mass Spectrometry, 2002, Vol. 16, No. 9, 879-883.

15. Fitzgerald R, O'Neal C, Hart B, Poklis A, and Harold D. Comparison of an Ion Trap and a Quadrupole Mass Spectrometer using Diazepam as a Model Compound. Journal of Analytical Toxicology, Vol. 21, No. 6, 1997, 445-451.

16. Kintz P, Tracqui A, and Mangin P. Sweat Testing for Benzodiazepines. Journal of Forensic Sciences. Vol. 41, No. 5, 1996, 851-854. 